\title{
Las Lunas, Yuncler (Toledo). Un depósito de materiales metálicos del Bronce Final en la Submeseta Sur de la Península Ibérica
}

\author{
Las Lunas (Yuncler, Toledo). A Bronze Age hoard with metallic materials \\ from the southern Iberian Meseta
}

\author{
Dionisio Urbina Martínez (*) \\ Óscar García Vuelta (**)
}

\begin{abstract}
RESUMEN
Se exponen los resultados del primer estudio realizado sobre un nuevo conjunto de materiales metálicos del Bronce Final recuperado a finales de 2008 en las excavaciones arqueológicas del yacimiento de Las Lunas (Yuncler, Toledo, España). La localización geográfica del hallazgo, lejos de las principales zonas de dispersión conocidas para este tipo de conjuntos, la singularidad de los objetos que integra, y las relaciones atlánticas y mediterráneas que evidencian sus materiales, lo convierten en un ejemplo destacado para el estudio de este período en el centro de la Península Ibérica.
\end{abstract}

\begin{abstract}
Here we present the results of the preliminary study carried out on a new group of metallic materials of the Final Bronze Age, recovered at the end of 2008 in the archaeological excavations at the settlement of Las Lunas (Yuncler, Toledo, Spain). Its geographical situation far away from the main zones of distribution of this type of finds, the singularity of the materials, and the evidence of Atlantic and Mediterranean relations make these materials a remarkable sample for the study of the Final Bronze Age in the centre of the Iberian Peninsula.
\end{abstract}

Palabras Clave: Hachas de talón; Fíbula de codo, Depósitos; Análisis XRF; Bronce Final Atlántico; Horizonte precolonial; Meseta Sur.

(*) Doctor en Geografía e Historia. Arqueólogo. C/Llano 25, Santa Cruz de la Zarza, Toledo 45370. Correo electrónico: d.urbina@yahoo.com

(**) Grupo de investigación Arqueometal, Instituto de Historia, Centro de Ciencias Humanas y Sociales, CSIC. c/Albasanz 26-28. Madrid 28037.

Correo electrónico: oscar.gvuelta@cchs.csic.es

Recibido: 12-XI-2009; aceptado: 20-I-2010.
Key words: Palstaves; Elbow fibula; Hoards; XRF analysis; Atlantic Late Bronze Age; Precolonial horizon; Southern Iberian Meseta.

\section{INTRODUCCIÓN}

En el mes de agosto de 2008, las excavaciones arqueológicas realizadas en el poblado de Las Lunas (Yuncler, Toledo) permitieron recuperar un nuevo depósito de materiales metálicos del Bronce Final. Este conjunto está formado por una veintena de objetos de bronce, entre los que se hallan herramientas, piezas de adorno y restos de fundición, pudiendo considerarse - tanto por los materiales que incluye como por su contexto arqueológico- un ejemplo destacado entre los aparecidos hasta el momento en la Meseta Sur. En ese sentido, es importante señalar que a diferencia de otros muchos depósitos de materiales metálicos del Bronce Final de la Península Ibérica, el de Las Lunas ha sido recuperado en el interior de un poblado y en el transcurso de una excavación arqueológica. Ambos datos son de una gran relevancia en una región que se consideraba alejada de las principales áreas de dispersión de este tipo de conjuntos, y en la que predominaban hasta la fecha los hallazgos de materiales aislados y descontextualizados. Por otro lado, a la poco frecuente posibilidad de estudiar e interpretar el conjunto en su contexto arqueológico, se suma el interés que ofrece el estudio de cada uno de los diferentes grupos de materiales documentados, que en muchos casos ofrecen cuestiones abiertas en su investigación. Finalmente, las influencias 
atlánticas y mediterráneas manifiestas en las piezas de las Lunas aportan nuevos datos al debate sobre el horizonte precolonial en la Península Ibérica (Celestino et al. 2008).

El objetivo de estas páginas es presentar estos materiales al colectivo científico, sin pretender agotar los sugerentes temas que se derivan tanto del análisis pormenorizado de las piezas como de la propia interpretación del conjunto y del yacimiento en el que fue recuperado, temas que serán abordados en detalle en próximos trabajos.

\section{EL POBLADO DE LAS LUNAS}

El yacimiento de Las Lunas está próximo a la localidad de Yuncler, en la comarca toledana de La Sagra (Fig. 1). Se asienta sobre terrenos de suaves lomas arenosas hoy desprovistas de cubierta vegetal, aunque en la toponimia y la vegetación de la zona quedan indicios de la antigua existencia de pequeñas lagunas alimentadas por los cauces de tres arroyos, de las cuales aún se conservan algunas manchas de terreno encharcadas. El yacimiento ha dejado una huella perfectamente reconocible en el paisaje, que se extiende por unas 10 ha. Este hecho es en sí mismo excepcional, pues hasta hace poco se consideraba que los asentamientos del Bronce Final/Hierro I en la región eran de pequeño tamaño, e incluso de carácter estacional (Blasco 2007), con excepciones como la de Ecce Homo, con una extensión próxima a las 5 ha (Almagro Gorbea y Fernández-Galiano 1980).

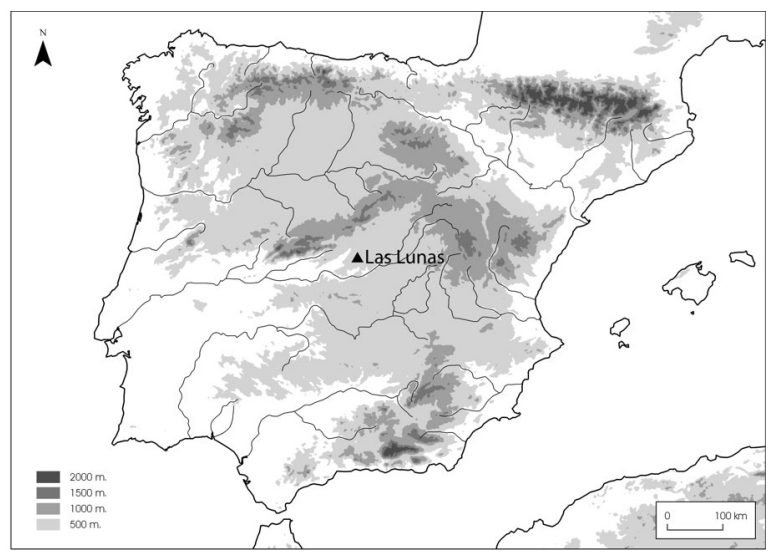

Fig. 1. Mapa de situación del depósito de piezas de Bronce de Las Lunas (Yuncler, Toledo).
La actuación arqueológica en la que se produjo el hallazgo afectó únicamente a 1 ha del yacimiento (1) y permitió documentar dos momentos de ocupación: uno correspondiente a época romana y otro al período del Bronce Final y Hierro I. Dentro de este último, fue posible diferenciar a su vez cuatro fases constructivas sucesivas. La más antigua se identifica arquitectónicamente con estructuras caracterizadas por pequeñas zanjas, de apenas $10 \mathrm{~cm}$ de ancho y una profundidad de 5 a $15 \mathrm{~cm}$, pertenecientes a cabañas de tendencia circular u ovalada, con tamaños entre 20 y $40 \mathrm{~m}^{2}$, aunque existe algún ejemplo de cabaña larga absidada que puede llegar a los $60 \mathrm{~m}^{2}$. La siguiente fase se correspondería con estructuras definidas por agujeros de poste, identificándose hasta el momento 5 cabañas de este tipo, con plantas ovaladas y entradas orientadas al E cuyas superficies oscilan desde los 35 a $70 \mathrm{~m}^{2}$. A la tercera fase de ocupación tan sólo se pueden asociar ciertas alineaciones de agujeros de poste, al haber sido fuertemente afectada por los restos de época romana. La última fase identificada se documenta únicamente en algunas zonas no arrasadas por los niveles romanos, en forma de elementos aislados aunque no carentes de interés. Este es el caso de una estructura rectangular con paredes de barro, que constituye uno de los escasos ejemplos del poblado en los que se constatan niveles afectados por el fuego y donde existen indicios de abandono precipitado.

Entre las producciones cerámicas, y a la espera de un estudio detallado de las mismas, se observan escasas variaciones en los niveles del Bronce Final, donde destacan por su abundancia los fragmentos de grandes contenedores, usualmente con las superficies exteriores escobilladas. Por lo que respecta a la cerámica fina, aparecen numerosas cazuelitas bruñidas con carenas altas, así como vasos de perfiles bitroncocónicos con decoración sobre el hombro a base de frisos incisos, a veces combinados con la excisión, en los que son frecuentes los mamelones con perforación horizontal sobre la propia carena. Aunque los acabados suelen ser reductores, negros en su mayoría, no faltan ejemplos bruñidos con acabados rojos a la almagra. En los niveles superiores correspondientes al

(1) Véase Urbina, D. y Urquijo, C. (en prensa): "El yacimiento de Las Lunas, Yuncler (Toledo): una ciudad de cabañas". Segundo Simposio Audema. El Primer Milenio a.C. en la Meseta central. De la longhouse al oppidum (Madrid, octubre 2008). Universidad Complutense. 
inicio de la Edad del Hierro, junto a los tipos descritos que perviven, aparecen también algunos cuencos pintados postcocción, destacando los que presentan motivos geométricos en amarillo sobre fondo rojo, así como los cuencos troncocónicos de base plana o umbilicada con mamelones de perforación horizontal junto al borde, que aparecen ya en las necrópolis del Primer Hierro de la zona (p. ej. Penedo et al. 2001).

Entre los elementos metálicos hay largos pasadores con cabeza redondeada o trapezoidal característicos de momentos del Bronce Final, junto a otros como una pulsera recuperada en el sector C5, con paralelos en necrópolis del Primer Hierro como la cercana de Arroyo Culebro (Penedo et al. 2001) o la levantina de Les Moreres (González Prats 2002). Se han descubierto asimismo indicios de actividad metalúrgica, evidenciados por varios acúmulos de escorias localizados en los sectores A2-B2 y H8 del poblado, o por un fragmento de molde de fundición aparecido en el talud del borde meridional de la zona excavada.

No obstante, estos datos deben manejarse con precaución, pues el yacimiento se encuentra todavía en una fase de análisis.

Sin duda uno de los aspectos más destacables del poblado de Las Lunas es la abundancia y complejidad de las estructuras documentadas. A pesar de que distintos agentes alteraron los restos de los niveles arqueológicos del Bronce Final/Hierro I impidiendo una visión de conjunto de toda el área, las evidencias de estructuras de habitación conforman un denso y complejo entramado de huellas de agujeros de poste y pequeñas zanjas, de entre las cuales hemos podido diferenciar al menos una veintena de cabañas. Para dar una idea de esta complejidad, mencionaremos que se han cartografiado 1900 agujeros de poste y que se han exhumado más de 90 hogares o estructuras de combustión. Un entramado arquitectónico de tales dimensiones nos resulta hasta el momento desconocido en los yacimientos de este período en el centro peninsular (2).

\section{EL CONJUNTO DE MATERIALES METÁLICOS}

El depósito (Lám. I, Figs. 3 a 5) está compuesto por un total de 20 objetos de bronce, incluyen-

(2) Véase nota 1. do piezas completas e incompletas junto a restos de fundición, con un peso conjunto de ca. $5635 \mathrm{~g}$. Los materiales mejor representados son las herramientas, recuperándose 8 piezas en su mayor parte completas: dos hachas de talón y dos anillas; dos hachas planas con una anilla; un martillo y una punterola de cubo; un punzón cuadrangular completo y otro fragmentado. Se localizaron también tres piezas de adorno con decoración geométrica incisa: un fragmento muy deteriorado de brazalete, otro correspondiente probablemente al puente de una fíbula de codo de considerables dimensiones, y una aguja o punzón aparentemente completa, con decoración muy similar a la de la pieza anterior. Además, hay que sumar un objeto con forma de manilla o asa y decoración sogueada, con paralelos en la región centro-sur de Portugal y Cerdeña (Taramelli 1921; Lopes y Vilaça 1998; Vilaça 2004, 2008; Armada et al. 2008; Arruda 2008). El inventario del conjunto se completa con 8 restos de fundición, entre ellos el cono de llenado de un hacha de talón y otro cono que pudo corresponder a un hacha plana, junto a salpicaduras, goterones y restos de colada en molde.

En el momento de su recuperación las piezas, actualmente restauradas, estaban muy mineralizadas y afectadas por la corrosión. La mayoría de los objetos, y en especial los de mayor tamaño, presentaban además profundas grietas y deformaciones, coincidiendo generalmente con las zonas de arista, así como diversas roturas superficiales. Estas características afectaban a todo el grupo de las herramientas (L-1 a L-8), destacando el mal estado de la punterola L-6, que hizo necesaria su

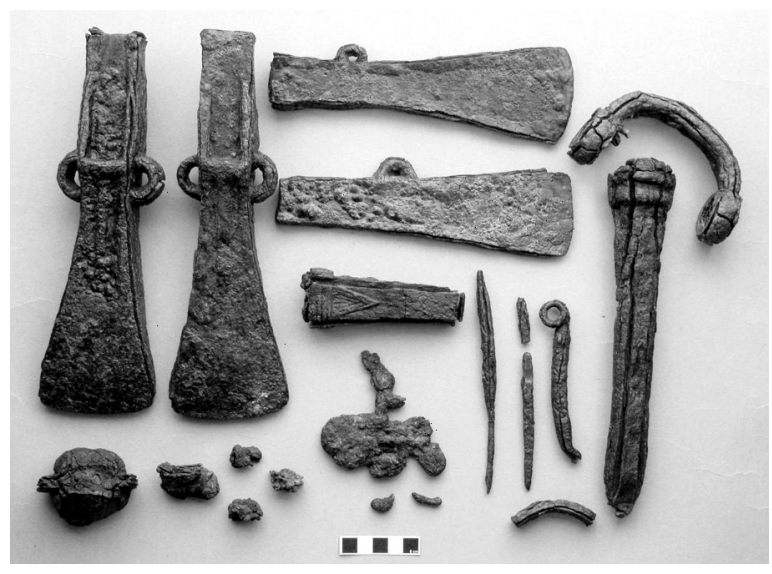

Lám. I. Materiales del conjunto de Las Lunas (Yuncler, Toledo), tras su restauración. Foto O. García Vuelta. 
reconstrucción, o las deformaciones observables en el martillo L-5. Las grietas y la corrosión perjudicaron igualmente a los objetos de menor tamaño (L-9, a L-12) y a los restos de fundición (L-13 a 20), impidiendo una adecuada reconstrucción de la secuencia ornamental de las piezas (L-11).

\subsection{Contexto del hallazgo}

Las piezas fueron descubiertas en el sector sureste -H8- del área excavada, en un estrato arenoso, sobre una superficie ocre endurecida, con restos de barro quemado (Lám. III). Se encontraban en su mayor parte apiladas, con las dos hachas de talón dispuestas en la parte superior, reposando sobre las hachas planas, a cuyos lados se distribuía a su vez la mayor parte de los elementos de menor tamaño (Lám. II). Tres de los objetos -el martillo, la manilla y la punterola- estaban desplazados de su ubicación original, sin duda por acción de efectos postdeposicionales de carácter natural (Fig. 2). Estos materiales evidenciaban una línea hacia el E indicada por el marti1lo, recuperado apenas a $5 \mathrm{~cm}$ del apilamiento, la manilla, a unos $40 \mathrm{~cm}$ y la punterola, a ca. $95 \mathrm{~cm}$.

No hay evidencias estratigráficas o materiales de que las piezas fueran depositadas en un hoyo $\mathrm{u}$ otro tipo de estructura, por lo que suponemos que debieron apilarse directamente sobre el suelo, o bien dentro de algún contenedor que no ha dejado huellas en el registro arqueológico, como un ces-

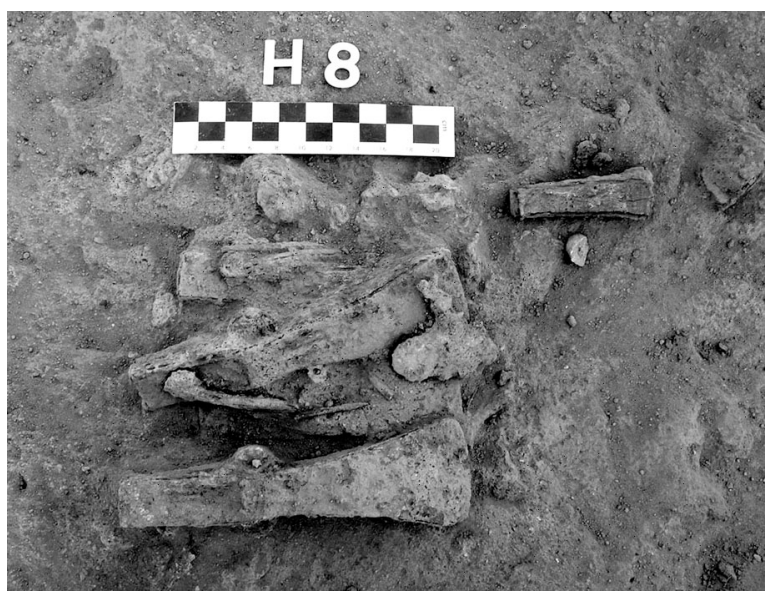

Lám. II. Detalle de la disposición de los materiales del conjunto de Las Lunas (Yuncler, Toledo), en el momento de su aparición. Foto D. Urbina.

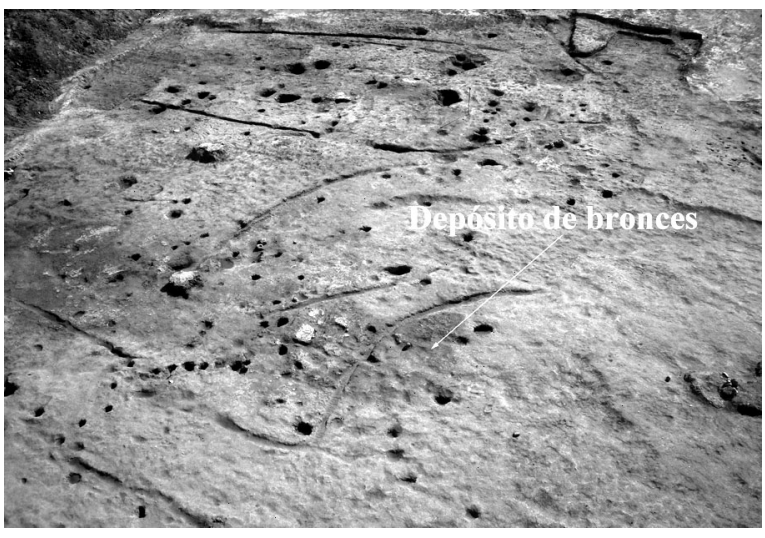

Lám. III. Detalle del área excavada en el poblado de Las Lunas (Yuncler, Toledo), con indicación del punto de aparición del conjunto de objetos metálicos. Foto D. Urbina.

to de mimbre, una caja de madera o un saquito de cuero.

Los bronces se hallaron junto al borde de una estructura de tendencia circular. Por desgracia, no se ha conservado la huella completa, de modo que no podemos conocer su planta exacta ni su extensión. El conjunto se asociaría en principio a la primera fase constructiva del poblado. Los ni-

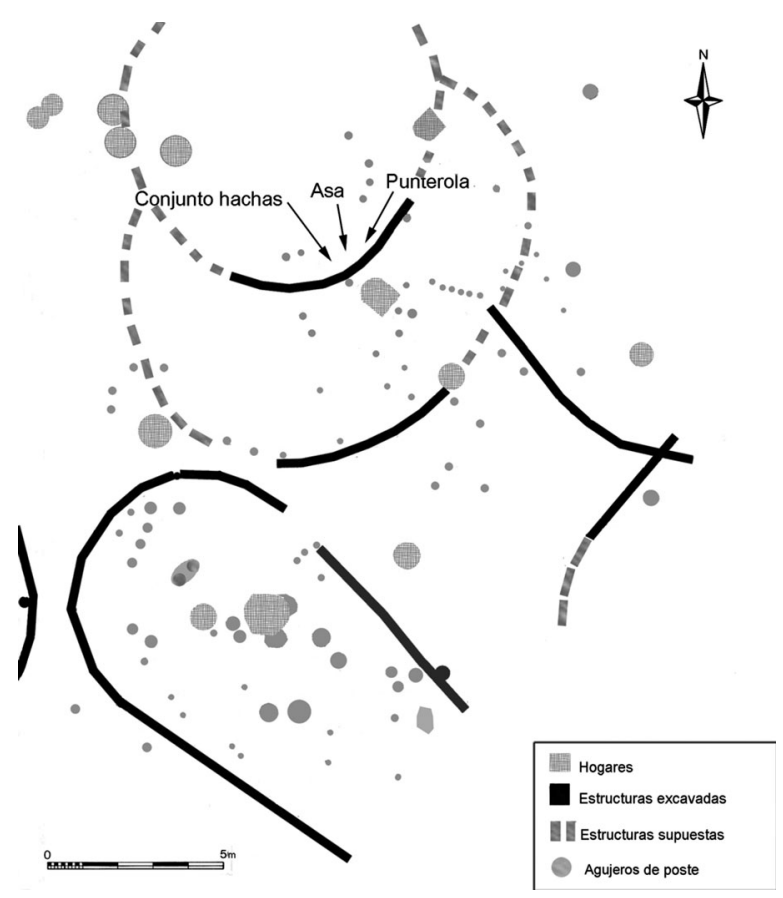

Fig. 2. Planta de las estructuras asociadas al conjunto de bronces en el poblado de Las Lunas (Yuncler, Toledo). 
veles de los suelos de ocupación de estas estructuras más antiguas están cubiertos por un estrato de $30 \mathrm{~cm}$ de potencia, formado por arenas sueltas de color parduzco, entre las que se hallaron numerosos restos cerámicos muy fragmentados y en su mayoría pertenecientes a grandes recipientes de paredes gruesas sin alisar. Estas características nos hacen pensar en un nivel de explanación, que sepultó los estratos entre los que estaba el conjunto metálico, a fin de disponer una nueva superficie. En ella han aparecido varios hogares, destacando el situado a unos $7 \mathrm{~m}$ al sureste, formado por 4 capas de fragmentos de vasijas rematadas por una superficie de tierra endurecida por el fuego. Entre ellos, se hallaron los restos de un cuenco con pintura postcocción a base de motivos geométricos en amarillo sobre fondo rojo. Estas cerámicas fueron clasificadas por Almagro Gorbea (1977: 460) en el grupo 4/ tipo Meseta, situándolas entre los siglos VII y V a.C. aunque estudios recientes han establecido su cronología desde el siglo IX a finales del VIII a.n.e. (Cáceres 1997: 137).

\subsection{Inventario (3)}

L-1. Hacha de talón con dos anillas (Fig. 3; Tab. 1, PA13502A y PA13502B: pieza de considerable grosor y cuerpo esbelto, que se ensancha desde la parte intermedia conformando un filo de desarrollo amplio, asimétrico y ligeramente ladeado. Los planos frontal y posterior incluyen acanaladuras de ca. $6,5 \mathrm{~cm}$ de longitud que parten de la garganta de tope, de $1,3 \mathrm{~cm}$ de altura. Las paredes laterales son prácticamente rectas y están bien repasadas. Las anillas ofrecen una notable anchura, situándose su arranque a la altura de la garganta. La base del hacha tiene sección rectangular.

Dimensiones $(\mathrm{cm})$ y peso: longitud: 24,7 ; anchura máx.: 7,5; anchura zona con anillas: 6,9 ; grosor máx.: 4,5 cm. Anillas: diámetro máx: 3,3 y 3,6; diám, mín: ca. 1,7 y 2; anchura: 1,8 y 2,1; grosor: ca. 1,2. Peso: 1614,77 g.

L-2. Hacha de talón con dos anillas (Fig. 3; Tab. 1, PA13503A y PA13503B): muy similar

(3) Todos los objetos del conjunto se han pesado en los laboratorios de Arqueología del CCHS, CSIC, empleando una balanza de precisión (Kern-EW), con límite de $3 \mathrm{~kg}$. Para los materiales más ligeros los resultados se han contrastado con una segunda balanza de precisión (Gibertini Crystal 100 SMI), con límite de $110 \mathrm{~g}$. a la anterior, con filo ligeramente ladeado. La garganta de tope tiene una altura máxima de $1,15 \mathrm{~cm}$.

Dimensiones $(\mathrm{cm})$ y peso: longitud: 24,9 ; anchura máx.: 7,7; anchura zona con anillas: 6,6 ; grosor máx.: 4,5. Anillas: diámetro máx.: 3,2 y 3,3; diámetro mín.: 1,8 y 1,9; anchura: 1,7 y 1,8; grosor: 0,9 y 1 . Peso: $1613,01 \mathrm{~g}$.

L-3. Hacha plana con una anilla (Fig. 3; Tab. 1, PA13505A y PA13505B): cuerpo de forma trapecial, con lados rectos que se ensanchan desde la anilla hasta formar un filo abierto. Destaca el pequeño tamaño del orificio de la anilla de suspensión, muy cerrada, y el desigual estado de conservación de los planos del ejemplar, observándose en uno de ellos un rehundimiento de la superficie en la zona central no apreciable en el opuesto, muy afectado por la corrosión. Entre la anilla y la base, de sección rectangular hay ca. de $4 \mathrm{~cm}$.

Dimensiones $(\mathrm{cm})$ y peso: longitud: 20,1 ; anchura máx.: 6,4; anchura zona con anilla: 4,2; grosor máx.: 1,75; grosor medio: 1,4. Anilla: diámetro máx.: 2,1; diám. mín.: 1,3; anchura máx.: 1,1; grosor máx.: 0,85. Peso: 592,50 g.

L-4. Hacha plana con una anilla (Fig. 3; Tab. 1, PA13504A y PA13504B). De tipología próxima a la anterior, aunque con significativas diferencias formales. Peso inferior, laterales más rectos y filo menos desarrollado. Su anilla, más abierta y de diámetro superior, está a una distancia de $6,1 \mathrm{~cm}$ del extremo posterior. Las características y estado de conservación de sus planos laterales son similares a los del ejemplar L-3.

Dimensiones $(\mathrm{cm})$ y peso: longitud: 19,6; anchura máx.: 5,8; anchura filo: 5,5; anchura zona con anilla: 5,1; grosor máx.: 1,3. Anilla: diámetro máx.: 2,95; diám. mín.: 1,4; anchura máx.: ca. 1; grosor máx.: 0,85. Peso: 457,87 g.

L-5. Martillo de cubo (Fig. 4; Tab. 1, PA13506): ejemplar de reducido tamaño con sección rectangular que se adelgaza desde la parte posterior a la frontal, ligeramente deformado. Presenta una zona distal moldurada de $1,5 \mathrm{~cm}$ de altura y motivos en relieve en $\mathrm{V}$ formados por 4 bandas paralelas en los planos laterales. La boca de enmangue es rectangular $(1,4 \times 1,6 \mathrm{~cm})$ y tiene una profundidad de $5,1 \mathrm{~cm}$. La parte activa, de ca. $2,45 \times 1,25 \mathrm{~cm}$ presenta bordes ligeramente redondeados. La pieza, fabricada en molde bivalvo, se encuentra bien repasada. En uno de los latera- 

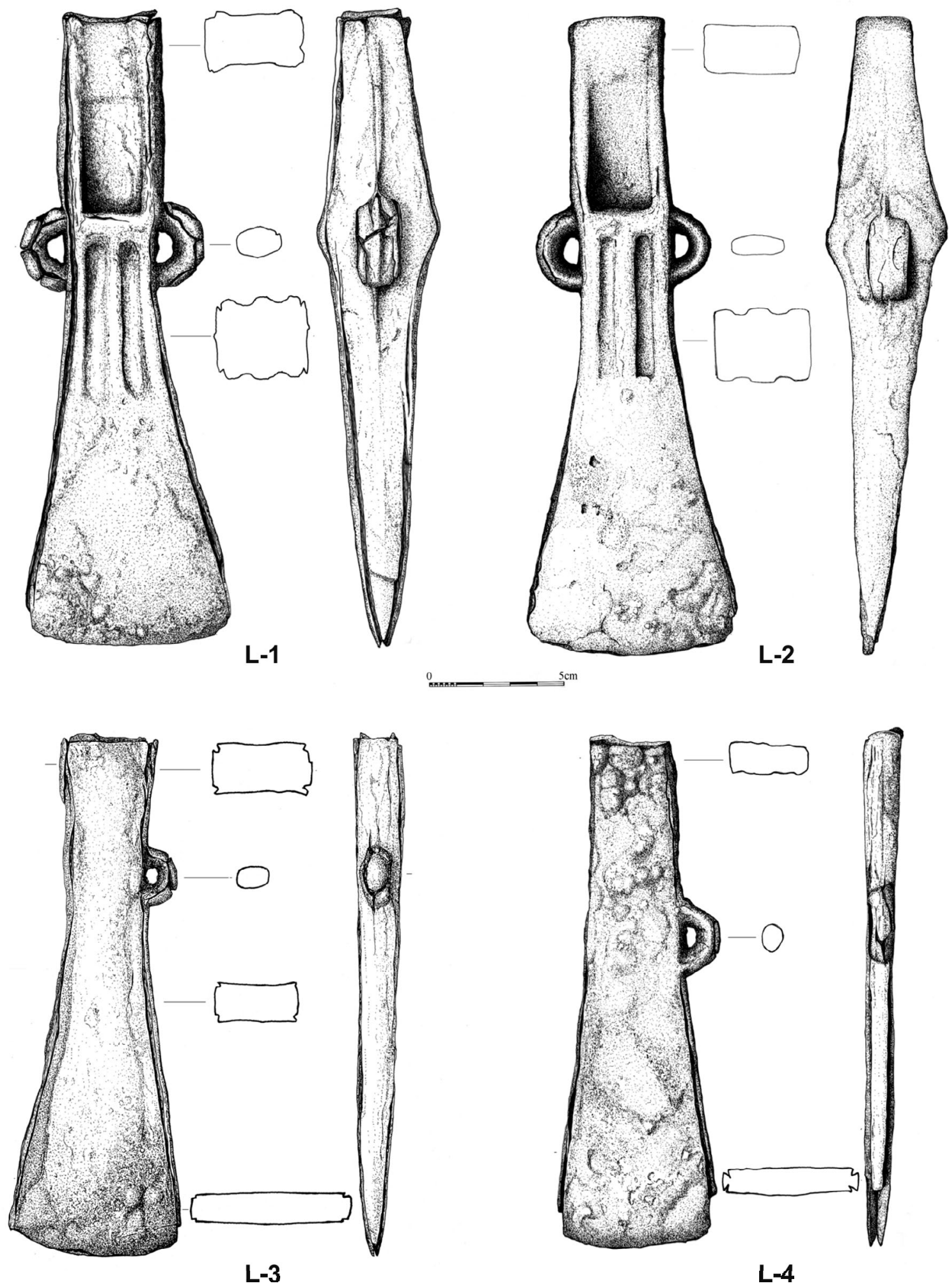

Fig. 3. Materiales del conjunto de Las Lunas (Yuncler, Toledo). Hachas de talón y hachas planas (L-1 a L-4). Dibujo de C. Urquijo.

T. P., 67, N. ${ }^{\circ}$ 1, enero-junio 2010, pp. 175-196, ISSN: 0082-5638 doi: $10.3989 /$ tp.2010.10035 
les de la parte distal se aprecia un pequeño espigón de ca. $3 \mathrm{~mm}$ de anchura.

Dimensiones $(\mathrm{cm})$ y peso: longitud: 10,7 ; anchura máx.: 3,95; grosor máx.: 2,8; grosor mín.: 1,5. Motivos en V: longitud: 3,1; anchura máx: ca. 2,2. Peso: 180,68 g.

L-6. Punta o punterola de cubo (Fig. 4; Tab. 1, PA13515): de considerables dimensiones, muy deteriorada faltando cerca de un tercio de su parte superior. Ofrece una zona distal moldurada de sección circular de 2,9 cm de altura, observándose restos de espigones en sus laterales. La boca de enmangue, incompleta, tiene ca. 1,8 $\times 1,5 \mathrm{~cm}$, y alcanza una profundidad de $9 \mathrm{~cm}$.

El cuerpo central presenta sección elipsoidal, con dos de sus lados aplanados, y está muy afectado por profundas grietas y fracturas. El grosor de las paredes pasa de $1 \mathrm{~cm}$ en la parte superior, a $0,5 \mathrm{~cm}$ hacia la zona central. Su extremo inferior es una punta redondeada, notablemente deformada.

Dimensiones (cm) y peso: longitud: ca. 23,5; diámetro máx.: 4,6; anchura máx.: 3,6; anchura mín.: 1; anchura media: 2,8; grosor medio: 2,3. Peso: $383,56 \mathrm{~g}$.

L-7. Punzón (Fig. 4; Tab. 1, PA13509): aparentemente completo, de sección cuadrangular, adelgazada progresivamente hacia el extremo inferior, y de superficie redondeada en el extremo superior, cuya sección es prácticamente rectangular (4).

Dimensiones $(\mathrm{cm})$ y peso: longitud: 9,1 ; anchura máx.: 0,7; anchura mín.: 0,3. Peso: 13,98 g.

L-8. Fragmento de punzón (Fig. 4.; Tab. 1, PA14001): corresponde en apariencia al extremo superior ligeramente apuntado de un punzón de sección cuadrangular, similar por sus dimensiones a la pieza L-7.

Dimensiones $(\mathrm{cm})$ y peso: longitud: 3,05 ; anchura máx: 0,6; anchura mín.: 0,35. Peso: 3,39 g.

L-9. Aguja o punzón decorado (Fig. 4; Tab. 1, PA13511): elemento de vestido o adorno aparentemente completo. El cuerpo central tiene sección subcuadrangular y está decorado con series de motivos geométricos incisos, que se interrumpen cerca del extremo superior, de menor grosor y

(4) Sus claras similitudes con el fragmento L-8, podrían hacer pensar en su pertenencia a un mismo objeto. Sin embargo, la no coincidencia de las zonas de sección y las diferencias de composición observadas en el estudio analítico (Tab. 1, PA13509-PA14001) no apoyan esta opción. Agradecemos al Dr. Ignacio Montero (CCHS, CSIC) sus precisiones en este sentido. sección rectangular. El extremo inferior se adelgaza para formar una aguja de sección circular de unos $5,5 \mathrm{~cm}$ de longitud, que se conserva fracturada. La decoración, mal conservada, alterna 3 bandas de reticulado con 2 bandas más anchas de motivos en aspa con perfil en $\mathrm{V}$. Todas las series quedan delimitadas por grupos de 2 ó 3 finas líneas horizontales. El patrón ornamental de esta pieza es muy similar al observable en el ejemplar L-10 del conjunto. Sin embargo no ha podido constatarse hasta el momento que ambos fragmentos, muy probablemente relacionados en origen, hayan podido formar parte de un mismo objeto (vide infra).

Dimensiones (cm) y peso: longitud: 14,7 ; grosor medio cuerpo: 0,9 ; grosor aguja: 0,5 ; Peso: $19,14 \mathrm{~g}$.

L-10. ¿Fragmento de fibula? (Fig. 4; Tab. 1, PA13508): pertenece probablemente al puente y parte del arranque de la aguja de una fíbula de codo decorada, de considerables dimensiones (vide infra). La zona identificable como la parte central del puente es de sección circular - elíptica y tiene un grosor medio de $1 \mathrm{~cm}$. La superficie del metal se adelgaza hacia la zona de arranque de la aguja, con sección circular y grosor medio de $0,5 \mathrm{~cm}$. La decoración geométrica incisa es muy similar en su composición y ejecución a la de la pieza L-9, comenzando en este caso las series de uno de los extremos con una banda de triángulos rayados.

Dimensiones $(\mathrm{cm})$ y peso: longitud: 10,7 . Puente: grosor máx.: 1,1; grosor mín.: 0,8; Aguja: grosor máx: 0,55. Peso: $36,37 \mathrm{~g}$.

L-11. Fragmento de brazalete (Fig. 4; Tab. 1, PA13510): de superficie biselada, muy deteriorado. Está decorado con series de motivos geométricos incisos, de las que conserva tan sólo algunos restos de líneas paralelas y zonas aisladas de reticulado, que no han permitido la reconstrucción de la secuencia ornamental.

Dimensiones $(\mathrm{cm})$ y peso: longitud: 5,5 ; anchura media, 1,3; grosor máx. aro: 1 ; grosor medio 0,75; desarrollo: ca. 6,5. Peso: 19,17 g.

L-12. Manilla o asa (Fig. 4; Tab. 1: PA13507): prácticamente completa, con cuerpo central en forma de $\mathrm{C}$, integrado por dos barras lisas de sección circular separadas por una barra torsionada. Los extremos están formados por voluminosas argollas circulares perpendiculares al cuerpo central. La cara interior de una de ellas tiene dos espigones dispuestos en paralelo en la 

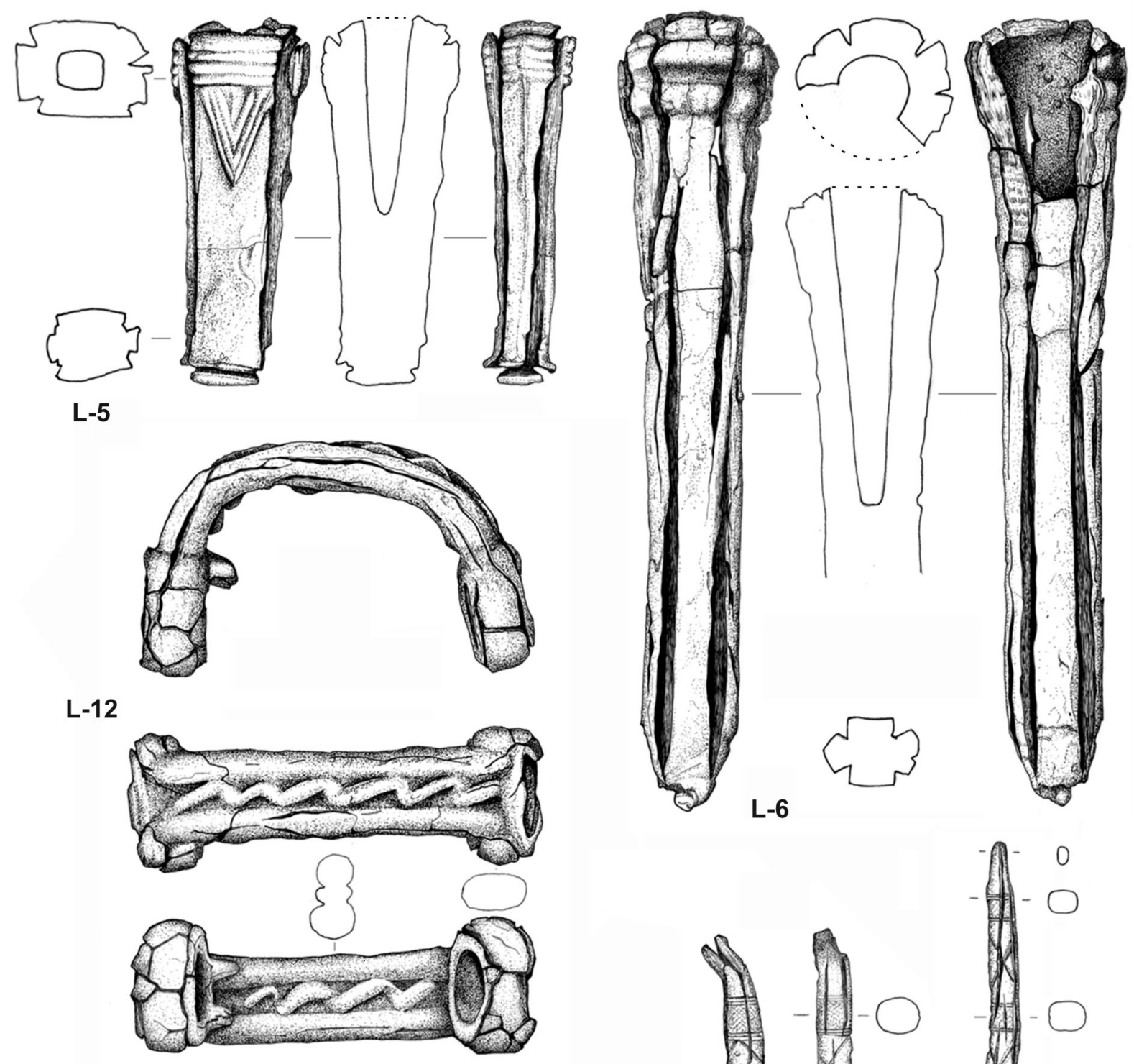

L-6

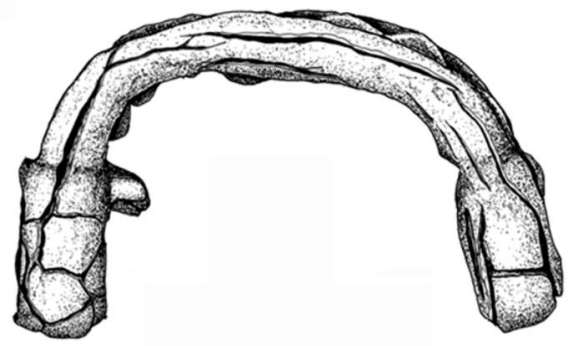

L-12

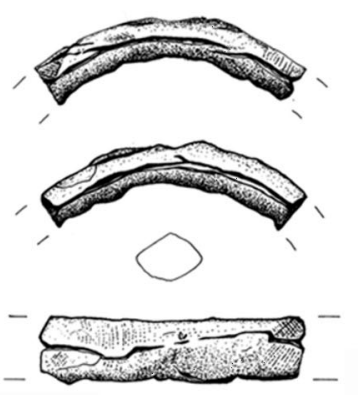

L-11
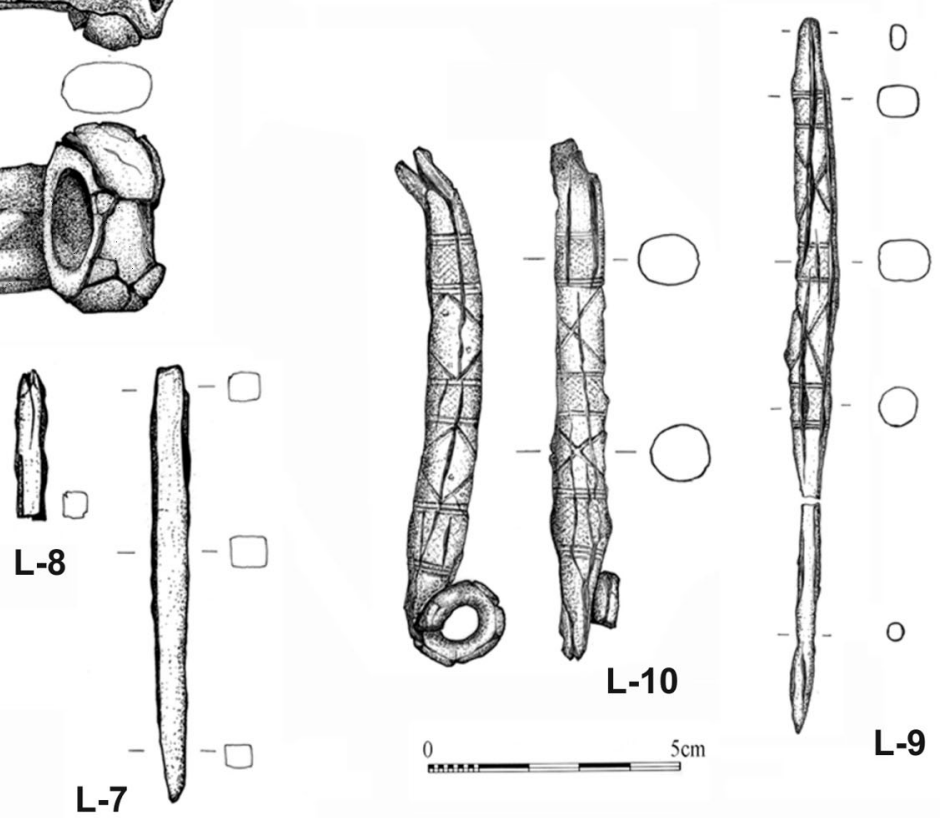

Fig. 4. Conjunto de Las Lunas (Yuncler, Toledo). Herramientas y objetos de adorno (L-5 a L-12). Dibujo C. Urquijo. 
parte superior. Posiblemente formaron parte de un sistema de sujeción o soporte. La pieza fue probablemente fabricada con la técnica del vaciado a la cera perdida, presentando algunas pequeñas fracturas y zonas de superficie irregular en el cuerpo central.

Dimensiones $(\mathrm{cm})$ y peso: diámetro (eje horizontal): 11,2; diámetro (eje vertical): 6,2. Aro: anchura media: 2,5; anchura máx.: 2,7; anchura mín.: 2,3; grosor máx.: 1,4. Anillas: diámetro máx. (eje horizontal): 3,9 ; diámetro máx. (eje vertical): 3,6 ; anchura máx.: 1,85; grosor medio 1,1. Espigones: longitud: 1. Peso: 247,3 g.

\section{Restos de Fundición}

L-13. Cono (Fig. 5; Tab. 1: PA13512): de sección circular, correspondiente a un hacha de talón. Conserva espigones laterales de sección rectangular y en la parte inferior una huella de corte, de ca. $2,1 \mathrm{~cm}$ de altura y $3,9 \mathrm{~cm}$ de anchura -correspondiendo ca. $3,2 \mathrm{~cm}$ al talón de la pieza-. Pudo pertenecer a una de las dos hachas de talón del conjunto (¿L-2?).

Dimensiones $(\mathrm{cm})$ y peso: altura: 3,5 ; diámetro máx. (eje vertical): 5,1 ; diámetro mín. (eje vertical): 3; anchura máx. (eje horizontal): 6,5. Espigones: anchura máx.: 1,1; grosor máx.: 1,05. Peso: 296,05 g.

L-14. Cono (Fig. 5; Tab. 1: PA13514): resultante de una colada en molde bivalvo. Su parte superior ofrece una superficie lisa, ligeramente inclinada, formando uno de los laterales un codo de superficie plana por la parte inferior e inclinada por la superior, de sección rectangular $(3 \mathrm{~cm} \times 1,15 \mathrm{~cm})$. Pudo pertenecer a un hacha plana.

Dimensiones $(\mathrm{cm})$ y peso: altura: 2,2 ; anchura máx.: 4; grosor máx.: 2,35. Peso: 47,92 g.

L-15. Salpicadura (Fig. 5; Tab. 1: PA13513): o adherencia, de superficie irregular por uno de sus lados y plana por el opuesto. Ofrece un estado de conservación desigual en ambas caras, así como algunas grietas.

Dimensiones $(\mathrm{cm})$ y peso: longitud: 8,8 ; anchura máx.: 8,5 ; grosor medio: 0,8 ; grosor máx.: 1,2. Peso: $97,11 \mathrm{~g}$.

L-16. Resto de colada (Fig. 5; Tab. 1: PA14000): de forma irregular en la parte superior; en la inferior, arranca una zona de sección rectangular $(\mathrm{ca} .1,35 \times 1,55 \mathrm{~cm})$ prácticamente perdida. Probablemente resto de una colada en molde que sirvió para elaborar un objeto con esta sección, quizá una barra o cincel.

Dimensiones $(\mathrm{cm})$ y peso: altura: 1,8 ; anchura máx.: 2,35; grosor mín.: 1,2. Peso: 11,02 g.

L-17. Resto de colada (Fig. 5; Tab. 1: PA13999): de forma irregular en la parte superior, fracturado en su parte inferior, con grietas en varios puntos de su superficie.

Dimensiones (cm) y peso: altura: 1,6 ; anchura máx: 2,35; grosor máx.: 1,4. Peso: 8,09 g.

L-18. Resto de colada (Fig. 5; Tab. 1: PA14002): de forma irregular, observándose profundas grietas en su superficie.

Dimensiones $(\mathrm{cm})$ y peso: longitud: 2,15 ; anchura máx.: 1,6; grosor máx.: 1,3. Peso: 6,72 g.

L-19. Goterón de fundición (Fig. 5; Tab. 1: PA14003): de superficie ligeramente redondeada, fracturado en un extremo.

Dimensiones $(\mathrm{cm})$ y peso: longitud: 1,6 ; anchura máx.: 1; grosor máx.: 0,7. Peso: 2,69 g.

L-20. Goterón de fundición (Fig. 5): conserva una zona con sección circular de grosor irregular y un extremo redondeado de superficie aplanada. Está mineralizado y afectado por corrosión.

Dimensiones $(\mathrm{cm})$ y peso: longitud: 2,05 ; anchura máx. (extremo): 0,6 ; grosor aro: 0,5 ; grosor extremo: 0,4; longitud extremo: 0,7. Peso: 1,29 g.

\subsection{Análisis de composición}

El estudio arqueométrico realizado sobre los materiales ha consistido en la determinación de su composición elemental mediante Fluorescencia de Rayos X (XRF) (5). Para ello, se ha utilizado un espectrómetro Meteorex X-MET 920MP con detector de $\mathrm{Si}(\mathrm{Li})$ y fuente de americio 241, instalado en el Museo Arqueológico Nacional. Los tiempos de adquisición se fijaron en $300 \mathrm{seg}$ y los valores cuantitativos fueron calculados a partir de patrones certificados. Los análisis se han expresado como porcentaje en peso de cada uno de los elementos detectados $(\mathrm{nd}=$ no detectado, $\operatorname{tr}=$ trazas). Hay que advertir sin embargo que debido a los límites de detección en las condiciones de análisis, cantidades inferiores al $0,1 \%$ para ní-

(5) Estos análisis han sido realizados por el Dr. Ignacio Montero Ruiz (CCHS, CSIC) en el marco del Proyecto Arqueometalurgia de la Península Ibérica. Agradecemos también al Dr. Salvador Rovira Llorens (MAN) la posibilidad de haber realizado estos trabajos. 

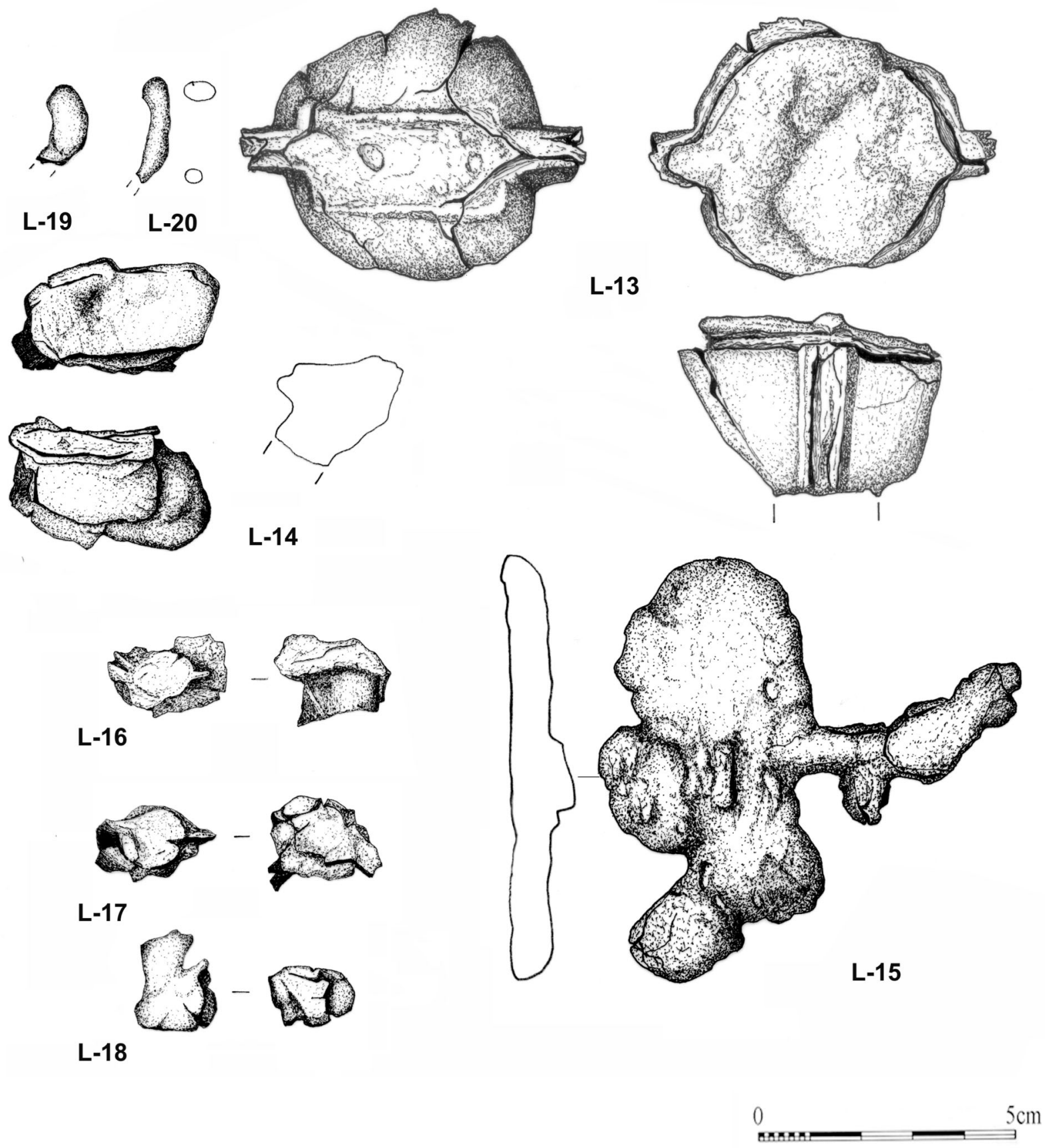

Fig. 5. Conjunto de Las Lunas (Yuncler, Toledo). Restos de fundición (L-13 a L-20). Dibujo C. Urquijo.

quel $(\mathrm{Ni})$, cinc $(\mathrm{Zn})$, arsénico (As) y bismuto (Bi) podrían existir.

Se han realizado un total de 23 tomas analíticas (Tab. 1) sobre 19 de los 20 objetos inventariados en el conjunto, con la excepción del resto de fundición mineralizado L-20. En todos los casos se ha procedido a una limpieza mecánica previa de la zona a analizar mediante abrasivo para eliminar la pátina superficial. Para evitar posibles errores derivados de la poca homogeneidad de las coladas, se han realizado dos tomas (filo y parte posterior) sobre las hachas planas y de talón (L-1 a L-4).

Los resultados obtenidos muestran unas aleaciones binarias $\mathrm{Cu}-\mathrm{Sn}$, con unos valores medios 


\begin{tabular}{|c|c|c|c|c|c|c|c|c|c|}
\hline ANÁLISIS & Pieza & $\begin{array}{c}\text { Inven- } \\
\text { tario }\end{array}$ & $\mathrm{Fe}$ & $\mathrm{Cu}$ & Ag & Sn & Sb & $\mathbf{P b}$ & Notas \\
\hline PA13502A & Hacha talón 2 anillas (talón) & L-1 & 0,37 & 87,7 & 0,153 & 11,8 & 0,016 & $\operatorname{tr}$ & Mineralizado \\
\hline PA13502B & Hacha talón 2 anillas (filo) & L-1 & 0,27 & 87,8 & 0,193 & 11,6 & 0,015 & 0,15 & Mineralizado \\
\hline PA13503A & Hacha talón 2 anillas (talón) & L-2 & 0,40 & 85,2 & 0,103 & 14,1 & nd & 0,12 & \\
\hline PA13503B & Hacha talón 2 anillas (filo) & L-2 & 0,29 & 91,3 & 0,040 & 8,13 & nd & 0,25 & Mineralizado \\
\hline PA13505A & Hacha plana 1 anilla (talón) & L-3 & 0,41 & 86,7 & 0,064 & 12,5 & 0,023 & 0,27 & \\
\hline PA13505B & Hacha plana 1 anilla (filo) & L-3 & 0,54 & 87,0 & 0,071 & 11,9 & 0,022 & 0,41 & \\
\hline PA13504A & Hacha plana 1 anilla (talón) & L-4 & 0,47 & 87,3 & 0,076 & 11,5 & 0,021 & 0,59 & \\
\hline PA13504B & Hacha plana 1 anilla (filo) & L-4 & 0,45 & 87,0 & 0,049 & 11,8 & 0,030 & 0,58 & \\
\hline PA13506 & Martillo de cubo & L-5 & 0,39 & 85,4 & 0,045 & 13,3 & nd & 0,86 & \\
\hline PA13515 & Punterola de cubo & L-6 & 0,42 & 86,5 & 0,052 & 12,4 & nd & 0,58 & Mineralizado \\
\hline PA13509 & Punzón sec. cuadrangular & L-7 & 0,26 & 90,7 & 0,052 & 8,52 & nd & 0,43 & Mineralizado \\
\hline PA14001 & Frag. punzón sec. rectangular & L-8 & 0,64 & 85,0 & 0,060 & 13,4 & 0,059 & 0,88 & \\
\hline PA13511 & Aguja o punzón decorado & L-9 & 0,69 & 87,4 & 0,063 & 10,9 & nd & 0,93 & \\
\hline PA13508 & Frag. ¿fíbula? & L-10 & 0,65 & 86,6 & 0,065 & 11,8 & nd & 0,85 & Mineralizado \\
\hline PA13510 & Frag. brazalete & L-11 & 0,43 & 89,0 & 0,054 & 9,82 & nd & 0,68 & \\
\hline PA13507 & Manilla o asa decorada & L-12 & 0,68 & 89,2 & 0,054 & 9,58 & 0,047 & 0,44 & Mineralizado \\
\hline PA13512 & Cono fundición hacha talón & L-13 & 0,33 & 87,1 & 0,049 & 12,1 & 0,009 & 0,44 & Mineralizado \\
\hline PA13514 & Cono fundición ¿hacha plana? & L-14 & 0,04 & 90,7 & 0,041 & 8,78 & 0,031 & 0,38 & Mineralizado \\
\hline PA13513 & Salpicadura fundición & L-15 & 0,47 & 87,2 & 0,091 & 11,8 & 0,041 & 0,38 & \\
\hline PA14000 & Resto colada & L-16 & 0,44 & 82,1 & 0,044 & 16,7 & 0,039 & 0,66 & \\
\hline PA13999 & Resto colada & L-17 & 1,19 & 83,5 & 0,041 & 15,2 & 0,026 & nd & \\
\hline PA14002 & Resto colada & L-18 & 0,48 & 88,5 & 0,110 & 10,3 & 0,072 & 0,57 & \\
\hline PA14003 & Goterón fundición & L-19 & 0,65 & 88,4 & 0,043 & 9,62 & 0,068 & 1,23 & \\
\hline
\end{tabular}

Tab. 1. Resultados de los análisis XRF realizados sobre los materiales del conjunto de Las Lunas (Yuncler, Toledo). Valores expresados en $\%$ en peso (nd = no detectado).

bastante característicos en la metalurgia del Bronce Final de la Península Ibérica. Tan solo en una de las tomas (PA14003), correspondiente al resto de fundición L-19 el valor de plomo es superior al $1 \%$. Los valores de estaño oscilan en la mayoría de los casos entre el 9 y el $14 \%$, superándose ligeramente este valor en los análisis PA13999 y PA14000, correspondientes a los restos de fundición L-17 y L-16 respectivamente. Estos valores se aproximan a los obtenidos para otros hallazgos de estas regiones, como el depósito de armas de Puertollano, en Ciudad Real (Montero et al. 2002: 19; Fernández y Rodríguez de la Esperanza 2002), y se alejan de las aleaciones ternarias $\mathrm{Cu}-\mathrm{Sn}-\mathrm{Pb}$ documentadas en hachas de talón del área Noroeste o la cornisa cantábrica, fechadas probablemente ya en momentos avanzados del Bronce Final (Sierra et al. 1984; Rovira 1995: 53 y ss; 2004: 28, entre otros).

El estudio analítico de los materiales metálicos de Las Lunas no ha concluido; queda pendiente la comparación de los resultados obtenidos con los análisis por FRX de otros objetos, así como de las evidencias de producción localizadas en el poblado, actualmente en curso (6).

\section{APROXIMACIÓN AL ESTUDIO DE LOS MATERIALES}

Los materiales de Las Lunas cuentan con una representación desigual en el registro arqueológico conocido para el Bronce Final de la Península Ibérica, documentándose la convivencia de tipos de origen atlántico, mayoritarios en el conjunto, con objetos de clara influencia mediterránea. Tanto en uno como en otro grupo, las piezas constituyen en algunos casos ejemplos singulares, y en otros, parte de tipos cuya investigación sigue abierta.

(6) Se han obtenido también muestras para la realización de análisis de isótopos de plomo sobre las herramientas, objetos de adorno y restos de fundición del conjunto, que contribuirán a enriquecer su estudio con nuevos datos sobre las materias primas empleadas. 


\subsection{Las herramientas}

Los elementos del conjunto mejor documentados son las hachas de talón con dos anillas, tipo de origen atlántico que cuenta con abundantes ejemplares en la Península Ibérica, en contraste con su menor presencia en otras regiones europeas. Actualmente se acepta que surgen en la Europa Atlántica a partir de las hachas de rebordes, extendiéndose por regiones como el Sur de Inglaterra o Bretaña en el Bronce Final II, desarrollándose sucesivamente modelos de hachas de talón sin anillas, con una, y con dos anillas. El tipo se adoptaría en la Península Ibérica probablemente a partir de la importacion de modelos sin anillas, desde los cuales se iría configurando una producción de piezas anilladas a lo largo del Bronce Final III (Fernández Manzano 1986: 116 y ss). Por el contrario, la presencia de este tipo de hachas disminuirá a partir de estos momentos en otras regiones atlánticas (Fernández Manzano 1986: 39; Delibes et al. 1999: 90-91) e igualmente en el ámbito mediterráneo, documentándose, por ejemplo en el conjunto sardo de Sa Idda (Taramelli 1921: 22-24).

La dispersión de estas hachas muestra una clara concentración en el cuadrante Noroeste de la Península - especialmente en el Sur de Galicia y Norte de Portugal-. Buena parte de los estudios sobre estos materiales son de corte tipológico, destacando el extenso trabajo de L. Monteagudo (1977) (7). Posteriormente, diversos autores han estudiado nuevos hallazgos (p.e. Coffyn 1985) o matizado las clasificaciones previas (p.e. Díaz-Andreu 1988 o Delibes et al. 1999). Contamos con recientes aportaciones a escala regional (p.e. Herrán 2008), pero seguimos careciendo de publicaciones generales actualizadas o de una información suficientemente detallada para el adecuado estudio comparativo de todos los ejemplares conocidos, haciéndose necesarias nuevas revisiones de este grupo en el ámbito peninsular.

Los hallazgos de hachas de talón con anillas en la Submeseta Sur son escasos y se encuentran descontextualizados. Se conocen tres ejemplares con una anilla procedentes de Fuente Sabiñán y Rueda, en Guadalajara, y de Meco, en Madrid;

(7) Todavía de obligada referencia a pesar de que su excesivo número de grupos y subdivisiones que hacen la clasificación poco operativa, o de la poca homogeneidad en las descripciones de materiales. Sobre las críticas al trabajo de Monteagudo véase p.e. Díaz-Andreu 1988: 26-27. dos piezas con dos anillas de Cardenete, en Cuenca (Pereira 2007: 136) y Villaverde Bajo, en Madrid (Rodríguez y Rovira 2005-2007: 169), y otro ejemplar de talón de El Embocadero, en Torralba de Calatrava, Ciudad Real (Ciudad y Serrano 1986: 25-26; Benítez et al. 2004: 52; Pereira 2007: 136). Las dos piezas de Las Lunas se diferencian significativamente de las anteriores por su morfología, robustez y gran peso. En cambio, la semejanza entre ambas sugiere su procedencia de un mismo molde, correspondiendo quizá al hacha L-2 el cono de fundición L-13 del conjunto (Tab. 1, PA13512). A falta de un estudio exhaustivo de los posibles paralelos, y con las reservas expuestas anteriormente podríamos señalar también algunas similitudes con ejemplares procedentes principalmente de la Meseta y zona Norte, catalogados entre las variantes del grupo 32 de Monteagudo (1977: 189 y ss) (8).

Las hachas planas con anillas constituyen un tipo menos frecuente en la metalurgia peninsular del Bronce Final, con una dispersión más reducida que se concentra en la Meseta Norte (Delibes et al. 1994 y 1999: 97 y ss; Herrán 2008). Fuera de este ámbito, cuenta con algunos ejemplos en el área atlántica (Delibes et al. 1994: 262) y el mediterráneo central, en conjuntos sardos como Sa Idda o Flumenlongu (Taramelli 1921: 19-22; Lo Schiavo 1976: 9; Coffyn 1985: 146 y ss; o Bernardini 2008: 165). Se han planteado diferentes opiniones respecto a la funcionalidad, las relaciones y la génesis de este tipo, que ha llegado a considerarse propio de la Península Ibérica (Díaz-Andreu 1988: 39). Algunos autores las consideraron un modelo previo o prototipo de las hachas de talón, fechable en torno al Bronce Final I (Coffyn 1985: 199), otros en el Bronce Final III (Fernández Manzano 1986: 116-117). Los trabajos más recientes han apoyado esta datación, valorando su interpretación como tipo intermedio entre las hachas de talón y las de apéndices laterales, datable en torno al siglo VIII a.n.e. (Delibes et al. 1994: 248-251, 1999: 96 y 99; Herrán 2008: 315).

La mayoría de los ejemplares conocidos proceden de hallazgos aislados e incorporan dos ani-

(8) Pueden citarse como ejemplares con un peso inferior Huerta de Arriba, en Burgos (Monteagudo 1977: 195, n. ${ }^{\circ}$ 1232; Herrán 2008: 37) o Acera de la Vega, en Palencia (Monteagudo 1977: 197, n. ${ }^{\circ}$ 1244; Delibes et al. 1999: 87; Herrán 2008: 94); junto a otros de la provincia de Oviedo o de procedencia dudosa (Monteagudo 1977: 199 y 196, núms. 1267 y 1234). 
llas (9). En su día dos ejemplares, uno incompleto procedente de Quintana de Bureba, en Burgos (Monteverde 1969: 227) y otro de Dehesa de Romanos, en Palencia, fueron considerados como hachas con una anilla (Monteagudo 1977: 156, núms. 932 y 931) (10). Sin embargo, se han reinterpretado como hachas que incorporaron dos anillas originalmente (Delibes et al. 1994: 250; Delibes et al. 1999: 96 y 97 o Herrán 2008: 42 y 100).

Formalmente, las hachas de las Lunas - sin evidencias de la incorporación de una segunda anilla- se aproximan al grupo A1 definido por Delibes et al. (1999: 96) (11). Este grupo integra ejemplares con cuerpo trapecial y lados rectos, cuya anchura aumenta progresivamente desde la base hasta el filo, diferenciándose de los característicos meseteños de cuerpo esbelto y filo expandido.

En función de esta clasificación, y a falta de nuevos datos, el paralelo más cercano podría establecerse en una pieza del conjunto de Sotoscueva, que como el de Las Lunas, incorpora también hachas de talón con dos anillas (Delibes et al. 1994) (12). No obstante, podemos indicar también el reciente hallazgo de un molde de piedra para la fundición de hachas planas con una anilla en el yacimiento castellonense de Sant Joaquim, en la sierra de La Menarella (Pérez et al. 2007: 167, Fig. 122), que contribuye a confirmar la producción de este tipo, así como su aparición fuera

(9) Entre otros, pueden citarse los ejemplares burgaleses de Renedo de Aralla (Monteagudo 1977: 158, n. ${ }^{\circ}$ 938; Delibes et al. 1999: 96; Herrán, 2008: 44); Valdelateja (Monteagudo 1977: 158, n. ${ }^{\circ}$ 940; Herrán, 2008: 50) o Picocuerno, en Sotoscueva (Monteagudo 1977: 158, n. ${ }^{\circ}$ 937; Delibes et al. 1994); un ejemplar sin procedencia del museo de Burgos (Monteagudo 1977: 157, n. ${ }^{\circ}$ 934; Herrán 2008: 54); el leonés del Cerro de San Martín, en Reliegos (Herrán 2008: 74), y otra pieza de procedencia incierta del British Museum (Harrison y Craddock, 1981: 146, n. ${ }^{\circ} 89$, Fig. 17).

(10) Dando lugar al grupo 26 C de L. Monteagudo (1977: 156) -que incluye los ejemplares con dos anillas en su tipo $26 \mathrm{C}$ 2 (1977: 158)- y posteriormente al tipo 1.1. de Díaz-Andreu (1988: 39).

(11) En una de las más recientes propuestas de clasificación, estos autores dividen las hachas planas con anillas en dos grandes grupos, a partir de la incorporación (Grupo B) o ausencia (Grupo A) de esbozos de talón, diferenciando 2 variantes por grupo, en función de la presencia de cuerpos de forma trapecial (1) o cuerpos esbeltos con filo expandido (2) (Delibes et al. 1999: 97).

(12) Formado al parecer por 7 hachas, de las cuales 3 permanecen en paradero desconocido. El hallazgo incluye dos hachas de talón y dos anillas, pudiendo pertenecer quizá a un hacha plana con anillas otro fragmento del conjunto (Delibes et al. 1994: 241 y ss; Herrán 2008: 49 y 315). del ámbito de dispersión observado hasta el momento (13).

Los martillos de cubo constituyen otro tipo de origen atlántico documentado en la metalurgia europea desde la transición Bronce Medio-Final. En el contexto europeo, fueron estudiados por investigadores como A. Jockenhövel, que en función de su reducido tamaño medio planteó su posible uso en actividades artesanales metalúrgicas, como el repaso de piezas laminares de bronce (1982: 461; Barril et al. 1982: 381). Hasta el momento, su presencia es casi excepcional en el Bronce Final peninsular, aunque se conoce un ejemplar con procedencia incierta de Portugal (Coffyn 1985: 222), y un molde de fundición de Regal de Pídola, en Tamarite de Litera, Huesca (Barril et al. 1982: 375 y ss).

El martillo portugués ofrece notables diferencias formales con el de Yuncler, incorporando dos anillas y una nervadura central (Coffyn 1985: 222, Lám. LIII, 5). El molde de Tamarite representa un martillo de características formales más parecidas, con cuerpo esbelto, boca cuadrada y un motivo en forma de $\mathrm{V}$ invertida en los planos laterales (Barril et al. 1982: 375-78, Figs. 1, 2). Carece sin embargo de molduras en el cuerpo e incorpora un botón en resalte en el plano lateral, elemento ausente en el martillo de Las Lunas. El molde oscense se integra en un hallazgo casual formado por otros dos moldes de arenisca, uno para la fabricación de espadas y otro, múltiple, para fundir barras y agujas (Barril et al. 1982: 371 y 375). Originalmente se señaló su posible datación entre el Bronce Final III, por sus semejanzas con otras herramientas de enmangue tubular (vide infra) (14), y el Bronce Final II, en relación con el molde de espada de posible tipo Hemigkofen aparecido en el mismo conjunto (Barril et al. 1984: 377-378). Posteriormente, esta pieza se ha reinterpretado como un molde para espadas de lengüeta de tipo Valmaior, con una da-

(13) Agradecemos al Dr. X.L. Armada las primeras referencias sobre este molde y a D. ${ }^{\mathrm{a}} \mathrm{A}$. Barrachina habernos facilitado la mención a este hallazgo, aún en fase de publicación en el momento de redactarse estas páginas.

(14) La presencia de decoraciones en $\mathrm{V}$ se ha documentado también recientemente en otros moldes oscenses, como los empleados para la elaboración de cinceles de cubo procedentes del poblado de Vincamet [ver Gallart i Fernández, J. "El poblado de Vincamet (Fraga, Huesca): nuevos datos de la actividad metalúrgica de un asentamiento del grupo Segre-Cinca II (1250-950 cal. a.n.e.)". V Simposio Internacional Sobre Minería y Metalurgia Históricas en el Suroeste Europeo. Homenaje a Claude Domergue (León, 19-21 junio de 2008). En prensa]. 
tación más reciente en los campos de urnas antiguos (Brandherm 2007: 40-43, n. ${ }^{\circ} 21$ ).

Otras referencias formales próximas para estos martillos están en el grupo de las hachas de cubo sin anillas, estudiado por Hardaker (1976), Monteagudo (1977) o Coffyn (1985). Pueden mencionarse concretamente piezas con zona distal moldurada y decoraciones en $\mathrm{V}$ procedentes de los hallazgos catalanes de Ripoll o Tull (Martí 1969-1970: 129 y ss; Monteagudo 1977: 255, núms. 1754 y 1755; Pons 1979-1980: 62 y ss), o hachas con anillas y zona distal moldurada en los hallazgos de Santo Tirso o Barcelos, en el Norte de Portugal (Monteagudo 1977: 245, n. ${ }^{\circ} 1697$ y 1698). El reducido tamaño de los ejemplares conocidos de este grupo ha llevado a defender también su utilización en actividades artesanales (Hardaker 1976: 154). Finalmente, molduras y motivos en $\mathrm{V}$ se documentan también en otras piezas formalmente próximas, como los cinceles de cubo (vide infra).

El grupo de herramientas se cierra con un ejemplar de enmangue tubular, que interpretamos en función de su morfología como una punterola, y dos fragmentos de punzones de sección cuadrangular. Hasta el momento, no hemos documentado paralelos directos para la primera de estas piezas. Por su zona distal moldurada, podrían apuntarse también semejanzas con ejemplares del grupo de los cinceles de cubo datables en el Bronce Final III (Fernández Manzano 1986: 118-120), si bien éstos presentan un tamaño medio menor. Entre los materiales conocidos, cabría mencionar un ejemplar del depósito gallego de Hío, en Pontevedra (Monteagudo 1977: 249, n. ${ }^{\circ}$ 1714); los meseteños de Saldaña y Valderrábano (Palencia), o el de Otero de Sariegos, en Zamora (Herrán 2008: 107, Lám. 73,4; 108,111, Lám. 75; 169, Lám. 112). Cabe mencionar también un molde para la elaboración de ejemplares con decoraciones en $\mathrm{V}$ y zona distal moldurada en el yacimiento de Castell Salvà (Belianes, Lleida), o los recuperados en las excavaciones del poblado de Vincamet (Fraga, Huesca), recientemente presentados (15).

Los punzones de sección rectangular o cuadrangular y superficie lisa que cierran el inventario de herramientas constituyen un tipo bastante frecuente en la Edad del Bronce en diferentes regiones de la Península. Algunos autores se han

(15) Véase nota 13. ocupado de su estudio (Rovira y Gómez 1994), y contamos con algunas revisiones regionales (p.ej. Herrán 2008), pero el tipo carece de un catálogo actualizado. Como se ha señalado, la composición de los restos recuperados en Las Lunas, muy semejantes entre sí, indicaría la presencia de, al menos, dos punzones (Tab. 1, PA13509 y PA14001).

\subsection{Objetos de adorno y piezas de funcionalidad dudosa}

Por su estado de conservación o morfología, estas piezas ofrecen una interpretación compleja. Entre los primeros destaca un pequeño fragmento de brazalete o pulsera muy deteriorado con restos de decoración incisa, identificándose tan solo algunos restos de líneas paralelas y triángulos reticulados que no permiten una reconstrucción de su patrón ornamental (Fig. 6). Por su sección, podría considerarse entre las variantes del amplio grupo de brazaletes con secciones ovales, bien representado en diversas zonas del territorio peninsular (Lorrio 2008: 267 y ss). Su decoración de carácter geométrico es también frecuente entre los brazaletes del Bronce Final de diferentes áreas de la Península (Lucas et al. 2005-2006: 132-133; Lorrio 2008; 255 y ss, entre otros) (16).

Entre las piezas geográficamente más próximas, está un brazalete que apareció en superficie en el poblado de la Muela de Alarilla, en Guadalajara (Lucas et al. 2005-2006: 134-38), con ocupación de Cogotas I y Hierro Antiguo. Este ejemplar, cuya sección y dimensiones $-1,3 \mathrm{~cm}$ de anchura y $0,7 \mathrm{~cm}$ de espesor- tienen valores similares a las del fragmento de Las Lunas, conserva toda su decoración incisa (Lucas et al. 2005-2006: Lám. 2) aproximándonos al acabado final que pudo tener el fragmento toledano.

Otra de las piezas de mayor interés del conjunto de Las Lunas es el fragmento L-10, que por su morfología y decoración interpretamos como parte del puente de una fíbula de codo, un grupo que plantea todavía diversas cuestiones a debate.

(16) En el este peninsular, por ejemplo, podemos referirnos a depósitos como Sant Aleix o Llavorsí (Rovira y Casanovas 1993; Gallart 1991) con 17 y 77 brazaletes respectivamente, y en la Meseta, a algunos ejemplares con decoraciones incisas estudiadas por Herrán (2008) como Padilla de Abajo (Burgos) (pp. 41-42, Fig. 20), Poyato de la Armedilla (Valladolid) (Lám. 103, 1) y los leoneses de Villaverde de la Chiquita (pp. 85-86, Lám. 57), Cea (p. 63, Lám. 39, 1) y Astorga (pp. 157-158, Lám. 32). 

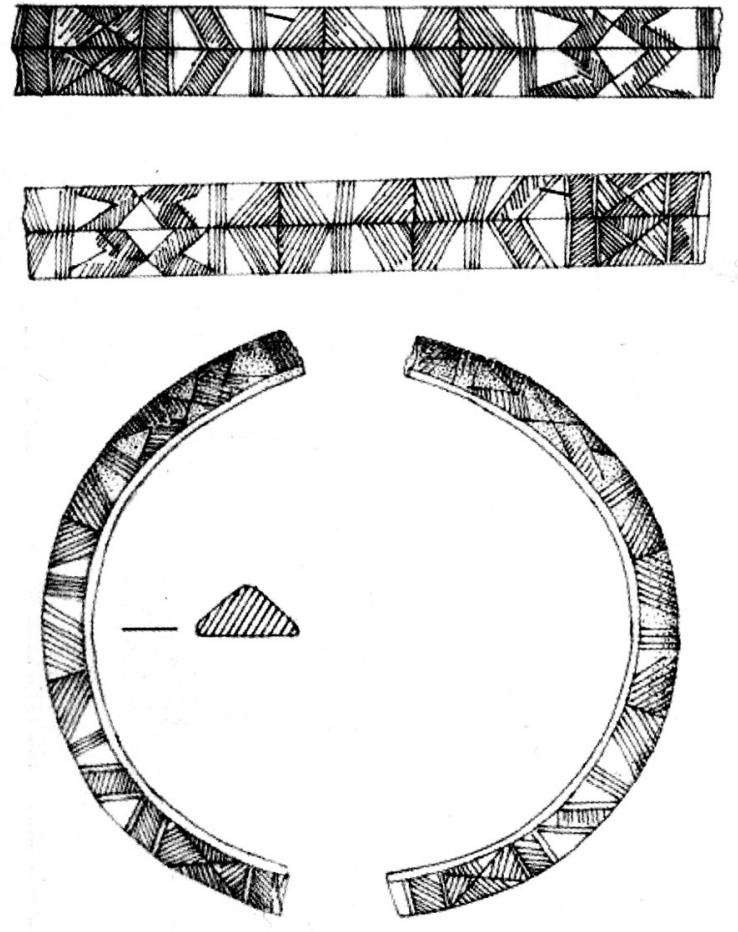

Fig. 6. Sección y desarrollo de la decoración del brazalete de la Muela de Alarilla (Guadalajara), según Lucas et al. 2005-1006: lám. II.

De confirmarse esta interpretación, se trataría de un ejemplar muy poco frecuente debido especialmente a su gran tamaño, que supera los $10 \mathrm{~cm}$ de longitud. Esta característica llevaría a relacionarlo con modelos de origen mediterráneo, concretamente con piezas sículas de los tipos Cassibile II y III, y en especial con los tipos 15D de la fase IIB de Cassibile (Turco 2000: 97). Estas fíbulas cuentan con escasos paralelos en la Península Ibérica, siendo el más cercano un ejemplar de procedencia incierta publicado por Almagro Basch (1957: 17 y 18) con 12,1 cm de anchura y $0,7 \mathrm{~cm}$ de grosor, y una decoración incisa próxima a la del fragmento de Las Lunas (Soriano 1991: 23 y 28) (Fig. 7) (17).

Otro ejemplar cercano al que nos ocupa aparece en el depósito de la Ría de Huelva, que algún

(17) Esta fíbula se ha hecho proceder de Levante, o del interior de Valencia o Castellón (Almagro Basch 1966: Lám. 3, n. ${ }^{\circ}$ 7) careciéndose en realidad de datos fiables sobre su lugar de hallazgo (Almagro Basch 1957: 39; Vives-Ferrándiz 2005: 69 , n. ${ }^{\circ} 8$ ). La pieza perteneció a la colección Martí Esteve, pasando posteriormente a las colecciones municipales del Museo de Valencia (Soriano 1991: 8, 23 y 28, n. ${ }^{\circ} 332$ ). autor considera el precursor de las fíbulas de codo que toman el nombre de este conocido depósito (Torres 1999: 171, Fig. VIII.5). Dentro de la misma categoría podría incluirse el ejemplar vallisoletano de San Román de la Hornija (Delibes 1978) o dos piezas portuguesas denominadas con arco serpeggiante a gomito de Sanfis (Mondim do Beira) y otra de Monte Airoso (Granja, Penedono) (Vilaça 2008: Fig. 4), aunque algunos autores las consideran algo más tardías (Carrasco y Pachón 2006a: 280). Puede mencionarse además el ejemplar ad occhio valenciano de la Mola d'Agres (Gil-Mascarell y Peña 1989) y, finalmente, la fíbula del Cerro de la Miel (Moraleda de Zafayona, Granada), considerada la más antigua (tipo I de Carrasco y Pachón 2006b: 109 y ss) y el prototipo del que derivarán las fíbulas de tipo Huelva (Carrasco y Pachón 2006a: 271).

Las fíbulas de codo tipo Huelva -dentro de las que habría que englobar el ejemplar del yacimiento madrileño de Perales del Río (Blasco 1987), el más próximo geográficamente a Las

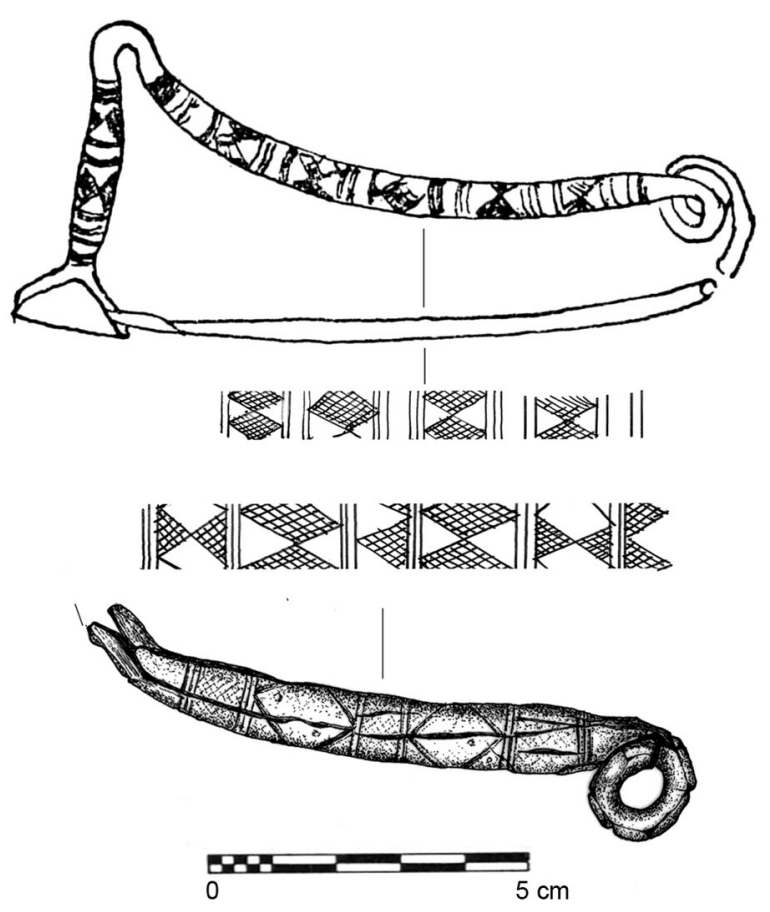

Fig. 7. 1. Fíbula con procedencia supuesta en la zona de Valencia o Castellón, publicada por Almagro Basch (1957: 17 y 18) y recogida por Soriano (1991: 23 y 28), con el desarrollo de su esquema decorativo. 2. Fragmento de Las Lunas, Yuncler (Toledo) con el desarrollo hipotético de su esquema decorativo. 
Lunas-, constituirían un grupo diferenciado para unos autores (Ruiz-Gálvez 1993: 49; Torres 1999: 171-2). Pero no todos aceptan la procedencia siciliana de los modelos que hemos relacionado más estrechamente con la fíbula de Las Lunas, esto es Cassibile II- III, así Carrasco y Pachón (2006a: 271 y ss) se inclinan por considerar un origen peninsular para todas las fíbulas de codo que llaman de tipo Huelva, en cuyo esquema evolutivo los ejemplares aquí reseñados constituirían los prototipos más antiguos.

Otro de los objetos del conjunto de Las Lunas, interpretable a priori como un alfiler o punzón decorado (L-9) presenta también diversos problemas de interpretación. No contamos con paralelos para este ejemplar, cuya ornamentación coincide en su técnica y composición con la documentada en la posible fíbula de codo L-10. Esta coincidencia podría hacer pensar en una relación entre ambas piezas. De confirmarse esta hipótesis, L-9 sería bien parte de otra fíbula en un estadio primario de elaboración o tal vez parte del mismo objeto que el fragmento L-10. Sin embargo, a pesar de su morfología, parece improbable que este ejemplar pudiera identificarse con la aguja de la mencionada fíbula o de otra similar, sin descartar una posible relación de origen entre ambos objetos.

El asa o manilla decorada L-12 constituye sin duda una de las piezas más singulares del conjunto. Por su morfología y técnicas de elaboración, encuentra sus paralelos más próximos en un reducido grupo de objetos estudiados en el marco de las relaciones o contactos entre la Península Ibérica y el Mediterráneo Central a finales del II milenio a.n.e. (Taramelli 1921; Lopes y Vilaça 1998; Vilaça 2004, 2008; Arruda 2008; Armada et al. 2008) cuya dispersión se limita a la zona Sur de Cerdeña y el centro-sur de Portugal (Fig. 8).
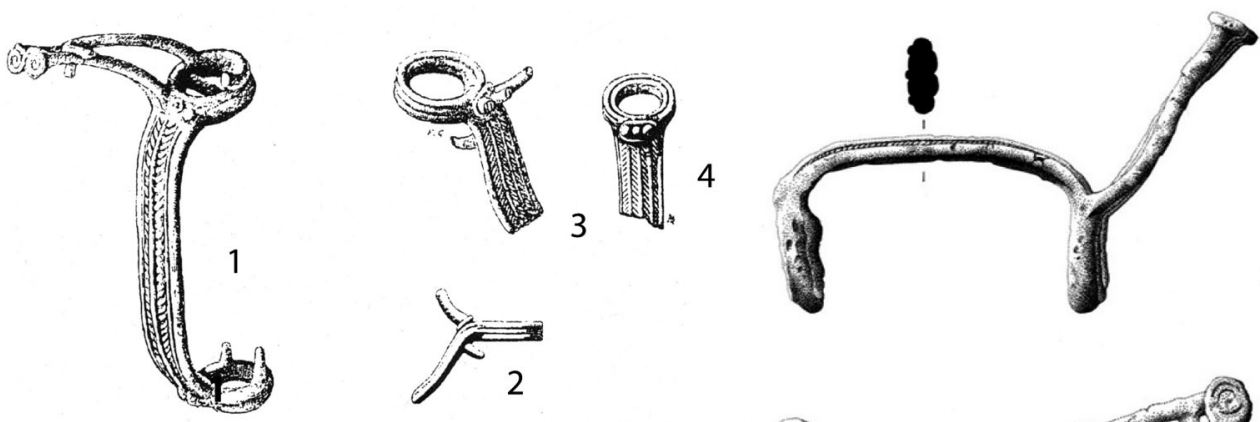

5
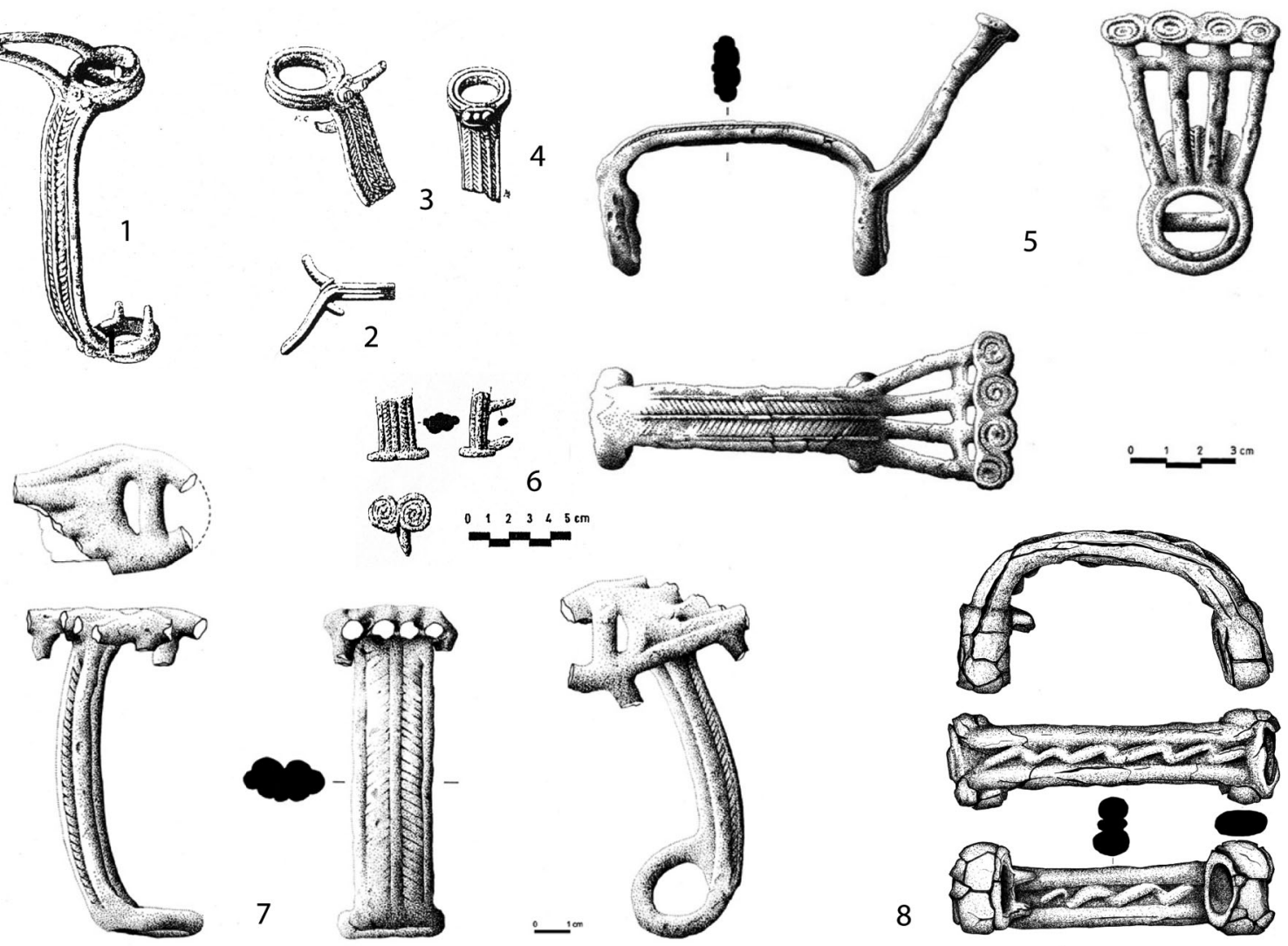

8

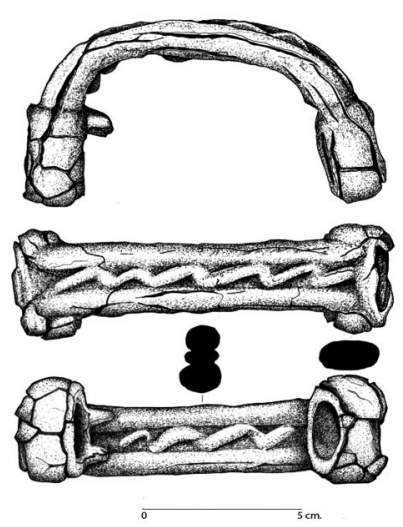

Fig. 8. Grupo de piezas con forma de asas o manillas y decoraciones en Y: 1 a 4. Monte Sa Idda (Cerdeña), según Tarame1li 1921; 5. Pé do Castelo (Trindade, Beja); 6. Castro de Pragança (Cadaval, Lisboa), según Lopes y Vilaça 1998; 7. Monte de Säo Martinho (Castelo Branco), según Vilaça 2004; 8. Las Lunas (Yuncler, Toledo). 
Se trata de piezas con forma de asa o manilla, fabricadas a la cera perdida, que incorporan un cuerpo central decorado con motivos en $\mathrm{Y}$ en composiciones de espina de pez o sogueados, y extremos rematados por voluminosas anillas en disposición perpendicular, que pueden incorporar travesaños interiores o pequeños espigones. Los ejemplares pueden incluir también apéndices ornamentales de notable desarrollo -vástagos y puentes de espirales- en la zona de contacto entre cuerpo y anillas.

Hasta la fecha se han identificado 7 objetos conservándose tan sólo uno completo. Los cuatro primeros, procedentes del conjunto de Monte $\mathrm{Sa}$ Idda (Fig. 8, n. ${ }^{\circ} 1$ a 4), fueron inicialmente interpretados como piezas tensoras de arco-tendiarco- a la espera de hipótesis más fiables (Tarame1li 1921: 59-60). En 1998, se publicó un ejemplar completo hallado casualmente en el poblado de Pé do Castelo (Trindade, Beja) (Fig. 8, n. ${ }^{\circ}$ 5), junto a un pequeño fragmento rematado con espirales del Castro de Praganza, en Cadaval, Lisboa (Lopes y Vilaça 1998) (Fig. 8, n. ${ }^{\circ}$ 6). El inventario se completó con otra pieza prácticamente completa, descubierta en el Monte de São Martinho, en Castelo Branco (Fig. 8, n. ${ }^{\circ}$ 7) probablemente a principios de los años 80 (Vilaça 2004).

La falta de contextos y de paralelos ha hecho que el estudio de estos materiales ofrezca aún diversas cuestiones abiertas, relativas fundamentalmente a su funcionalidad, origen y significado. Dejando de lado las primeras hipótesis, los últimos estudios han defendido su función de sujetar, fijar o suspender otros objetos, empleando para ello las anillas y/o los pequeños espigones que incorporan estas piezas. Esta idea, aplicable al ejemplar de Las Lunas, implicaría su uso en combinación con otros elementos, como piezas de madera o correas de cuero (Lopes y Vilaça 1998: 73; Vilaça 2004: 8, 2008: 393; Arruda 2008: 364; Armada et al. 2008: 488).

Sin embargo, a pesar de la uniformidad estilística observable en el grupo, las diferencias en la decoración y la presencia, morfología y disposición de los elementos funcionales y ornamentales de los objetos, podrían indicar variantes en su forma de uso o incluso distintas funcionalidades. En este sentido, se ha apuntado también su posible uso como adorno de mobiliario, con posibles paralelos en las asas o manillas de algunos cofres sardos, como el de Oschiri (Lopes y Vilaça 1998: 73; Vilaça 2004: 10, 2008: 393).
En función de su ornamentación a base de motivos en Y o en espiga (18), y su técnica de fabricación a la cera perdida, estas piezas se han estudiado en el marco de las relaciones entre la Península Ibérica y el Mediterráneo entre finales del II milenio e inicios del I milenio (Lopes y Vilaça 1998: 78; Vilaça 2004: 3 y ss; o Arruda 2008: 364), valorándose su importancia para el estudio de los contactos entre Cerdeña y el Centro de Portugal (Vilaça 2008: 393). Sin embargo, es difícil precisar con los datos actuales el carácter local o foráneo de los objetos, su valoración dentro de las comunidades indígenas (Vilaça 2004: 11-13), o la datación exacta de los materiales, al proceder éstos de hallazgos descontextualizados o de conjuntos -Sa Idda- que incorporan materiales de cronología diversa (Lo Schiavo 1991: 214, 220; Armada et al. 2008: 494).

Las características formales del ejemplar de Las Lunas justifican a nuestro juicio su relación con las piezas de este grupo (Fig. 8). Al menos con 6 de ellas comparte técnicas de fabricación y probablemente una misma funcionalidad. Elementos propios de estos objetos son también los pequeños espigones que observamos en la parte interior de una de las anillas de la pieza de Las Lunas. Sin embargo, no incluye características sobre las que se ha centrado su interpretación, como la decoración en Y (Lopes y Vilaça 1998: 74; Vilaça 2008: 392), los espigones ornamentales que, completos o incompletos, se observan en la mayoría de las piezas, o los travesaños que incorporan las anillas de los ejemplares mejor conservados (Sa Idda 1, Pé do Castelo, Sao Martinho). Sus dimensiones son también ligeramente superiores (Taramelli 1921: 60; Lopes y Vilaça 1998: 67; Vilaça 2004: 6), si bien no disponemos de estudios formales detallados para todos los ejemplares, una circunstancia que afecta igualmente a los estudios sobre la composición del metal (Vilaça 2004: 6) (19).

(18) Estas decoraciones se han relacionado con las influencias orientales que se manifiestan en el ámbito sirio-chipriota entre el II/I milenio a.n.e., adoptándose posteriormente en Cerdeña entre el 1300-900 a.n.e. (Lopes y Vilaça 1998: 74; Vilaça 2004: 10-11). En la Península Ibérica, se han relacionado con la de los bronces del depósito de Baiões, también considerada de influencia sirio-chipriota (Lopes y Vilaça 1998: 74-75; Vilaça 2004: 11 o 2008: 392; Armada et al. 2008: 487 y ss).

(19) Se ha publicado recientemente un análisis de composición por espectrometría de FRX del ejemplar de Castro de Pragança, con valores superiores de $\mathrm{Pb}$-entre 1 y $10 \%$ - y $\mathrm{Sn}$-entre 10 y $50 \%$ - (Figueiredo et al. 2007: 204). 


\section{INTERPRETACIÓN Y CRONOLOGÍA}

Destacamos, en primer lugar, la abundancia y diversidad de las herramientas de trabajo y su mejor estado de conservación respecto al resto de los objetos representados, pudiendo tratarse en su mayor parte de piezas en uso, que, como sucede con el martillo L-5, pudieron estar relacionadas con el trabajo artesanal (Vide supra). Por otro lado, elementos de adorno como los fragmentos de fíbula L-10 y de brazalete L-11- serían materiales amortizados destinados a la refundición y quizá ya en desuso en el momento de su deposición. Los restos de procesos metalúrgicos en el conjunto, como el cono L-13 y probablemente el L-14, se relacionan también con los tipos y objetos representados en el lote.

En principio, y aunque la interpretación de este tipo de hallazgos siempre constituye una cuestión compleja, pensamos que el conjunto puede interpretarse como un depósito de fundidor, configurado con materiales de origen diverso, de inspiración tanto atlántica como mediterránea, a los que se suman elementos derivados de una producción metalúrgica local señalada por los restos de fundición. Esta actividad local está confirmada también por la aparición en el poblado de moldes de fundición, y por concentraciones de escorias en diversas áreas del yacimiento. No debe extrañar la existencia de talleres metalúrgicos en poblados de la entidad del de Las Lunas, por más que hasta hace poco apenas contásemos con evidencias de los mismos. Los restos de hornos y fragmentos de toberas hallados recientemente en el poblado de cronología similar y relativamente cercano de Las Camas, en Villaverde Bajo (Urbina et al. 2007: 71 y ss) así parecen confirmarlo.

Los restos de fundición y los objetos de adorno ya deteriorados y en desuso, nos obligan a considerar, al menos parcialmente, el concepto de "chatarra de refundición" que utilizara Ruiz-Gálvez (2005: 254) para caracterizar otros conjuntos, como el de Baiões en Portugal, o la vivienda metalúrgica de Peña Negra en el levante español (Ruiz-Gálvez 1998: 253 y ss; 2005: 245 y ss).

La presencia de materiales de influencia mediterránea en este hallazgo, se encuadra en la interacción entre las comunidades atlánticas y mediterráneas. Se ha defendido que dicha interacción fue un proceso gradual, que parece consolidarse ya hacia el siglo XI a.n.e., jugando el Medite- rráneo central -Chipre y Cerdeña- un papel predominante. Estas relaciones se reflejan con más claridad en determinados puntos peninsulares, como Huelva, el centro de Portugal o el bajo Segura, presentando otras zonas, como la que nos ocupa, un mayor nivel de aislamiento (Armada et al. 2008: 504-505). En estos momentos, sin embargo, las comunidades locales ya contarían con un nivel de desarrollo económico y territorial suficiente como para el mantenimiento de unas relaciones de larga distancia, y probablemente también con redes de relación con otros puntos de la Península Ibérica.

\section{Cronología}

En el momento de redactar estas líneas contamos únicamente con una datación radiocarbónica para el contexto en el que aparece el conjunto de bronces del yacimiento de Las Lunas, Yuncler (Toledo) (Fig. 9). Fecha radiocarbónica: 2870 \pm 50 BP (Beta 251309). Su edad calibrada es 1020 BC con intervalos de probabilidad calibrados a 1 sigma (68\% de probabilidad) de $1120-980$ cal. BC, y 2 sigma (95\% de probabilidad) de 1210-910 cal. BC.

La muestra corresponde a fragmentos de madera quemada (que se están analizando actualmente) hallados a la entrada de una cabaña de planta absidada localizada unos $6 \mathrm{~m}$ al Sur del hallazgo metálico y perteneciente al mismo nivel estratigráfico.

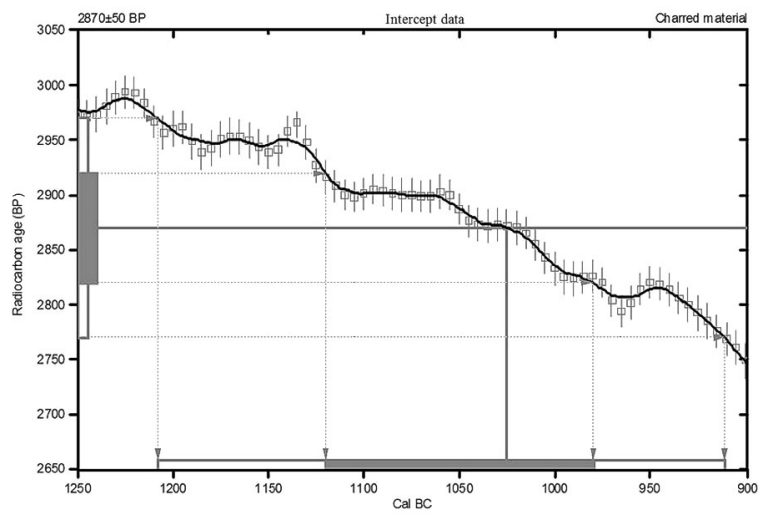

Fig. 9. Análisis C-14 de Las Lunas J8Nh3 (2). Beta Analytic Radiocarbon Dating Laboratory. Base de datos de calibración: Intcal 04, Calibration Issue of Radiocarbon (vol. 46, nr 3, 2004). Matemáticas: (Talma y Vogel 1993). Variables C13-C12=-25.2\%o. 
Teniendo en cuenta el material de la muestra, la fecha podría tal vez rebajarse un poco, situándonos en torno al cambio de milenio. Esta fecha se sitúa en pleno período del Bronce Final IIIA (como propone por ejemplo Mederos: 1050-950 (2008: 59)), o bien en sus inicios (Delibes et al. 2007: 125, Fig. 11). Existe una clara tendencia a subir las fechas en los últimos años. Por ejemplo Ruiz-Gálvez (1998: 208) situó el inicio del Bronce Final III a mediados del siglo $X$ a.n.e., tras revisar al alza la cronología de la Ría de Huelva (Ruiz-Gálvez 1995). De yacimientos más próximos a Las Lunas y ambientes culturales similares, contamos con fechas aún más altas, como Pico Buitre, en Guadalajara: $1238 \pm 90$ cal BC y 1112 \pm 90 cal BC (Arenas 1999: 194), o Guaya, cerca de Ávila: $1192 \pm 40$ cal BC, $1338 \pm 40$ cal BC (Misiego et al. 2005: 208-209). En torno al cambio de milenio se halla también la media ponderada de las fechas del cercano yacimiento de Las Camas (Urbina et al. 2007: 67-59).

Por otro lado, a la fase IIB de Cassibile, dentro de la que podría encuadrarse el posible fragmento de fíbula de codo de Las Lunas, se la asigna una cronología de la primera mitad del siglo IX a.n.e. (Turco 2000: 97). Aun con varios problemas, la fíbula de San Román de la Hornija se fecha dentro del siglo X a.n.e. (Delibes et al. 1995:58-59), entre el siglo X y IX el ejemplar valenciano ad occhio de la Mola d'Agres (Gil-Mascarell y Peña 1989), y fíbulas granadinas como la del Cerro de la Miel (Carrasco y Pachón 2006b). Estos autores rechazan la procedencia siciliana de los modelos que hemos relacionado más estrechamente con la fíbula de Las Lunas, liberándose de las cronologías sículas para centrarse en las peninsulares que abogan por el siglo XI a.n.e. como momento de comienzo del modelo, y fechan en el siglo X conjuntos tan conocidos como los de la Ría de Huelva o la Roça de Casal do Meio (Carrasco y Pachón 2006a: 283ss). Vemos, por tanto, que las fechas que se manejan para ejemplares como el aparecido en Las Lunas, coinciden grosso modo con las fecha de $\mathrm{C}_{14}$ de finales del XI - inicios del $\mathrm{X}$ a.n.e.

\section{CONCLUSIÓN}

A la espera de completar los estudios en curso, varios son a nuestro juicio los aspectos a destacar en el conjunto de Las Lunas. En primer lugar su propia composición: incluye herramientas y objetos de adorno con características formales heterogéneas que, en buena medida, apenas cuentan paralelos exactos entre los hallazgos peninsulares. No es de menor importancia el hecho de que junto a las hachas de talón con anillas, muy bien documentadas en este período, convivan otras piezas que confirman variantes de tipos ya conocidos fuera de sus ámbitos habituales de dispersión (hachas planas con una anilla) o materiales que reflejan el tránsito de influencias mediterráneas y atlánticas entre diferentes áreas geográficas (asa o manilla decorada y posible fíbula de codo).

En segundo lugar subrayamos el contexto de aparición de los objetos. El conjunto de Las Lunas constituye uno de los escasos ejemplos de depósitos localizados en el interior de un poblado y en el transcurso de una excavación arqueológi$\mathrm{ca}$, en un horizonte dominado por los hallazgos casuales y descontextualizados. Tan sólo sería parangonable, en la Meseta Sur, el también recientemente descubierto depósito de armas de Puertollano (Fernández y Rodríguez de la Esperanza 2002), si bien éste no pudo adscribirse a un yacimiento determinado. El hallazgo de Las Lunas adquiere un mayor interés si atendemos a la información que aportará la ingente cantidad de material arqueológico exhumado, en fase de estudio.

Podemos adelantar que el núcleo de habitación posee una notable extensión que alcanza las 8-10 hectáreas, y una gran complejidad estructural. Este tipo de yacimientos abre un horizonte mucho más rico de lo que se había llegado a suponer apenas hace unos años, que obligará, sin duda, a drásticas reformulaciones sobre el papel del centro peninsular en los procesos históricos del cambio del II al I milenio a.n.e.

Finalmente, la aparición de estos bronces en la Submeseta Sur añade, sin duda, nuevos argumentos de interés al debate actual sobre la etapa precolonial en la Península Ibérica, así como al estudio de las relaciones entre ésta y los ámbitos Atlántico y Mediterráneo (Celestino et al. 2008). En ese sentido, aspectos como la posible coexistencia de una fíbula de codo perteneciente a uno de los tipos más antiguos junto a materiales plenamente atlánticos como las hachas de talón, o como la integración en el conjunto de una manilla decorada que nos remite al centro de Portugal, reforzarían las tesis que defienden los contactos 
entre distintos ámbitos peninsulares y mediterráneos en fechas del cambio del II al I milenio a.n.e.

\section{BIBLIOGRAFÍA}

Almagro Basch, M. 1940: "El hallazgo de la ría de Huelva y el final de la Edad del Bronce en el occidente de Europa". Ampurias 2: 85-143.

Almagro Basch, M. 1957: "La fíbula de codo de la Ría de Huelva, su origen y cronología". Cuadernos de trabajos de la Escuela Española de Historia y Arqueología en Roma IX: 7-46.

Almagro Basch, M. 1966: "Sobre el origen posible de las más antiguas fíbulas anulares hispánicas". Ampurias 28: 215-236.

Almagro Gorbea, M. 1977: El Bronce Final y el Periodo Orientalizante en Extremadura. Bibliotheca Praehistorica Hispana XIV, CSIC. Madrid.

Almagro Gorbea, M. y Fernández-Galiano, D. 1980: Excavaciones en el cerro del Ecce-Homo (Alcalá de Henares, Madrid). Arqueología 2. Diputación Provincial de Madrid. Madrid.

Arenas Esteban, J. 1999: "El inicio de la Edad del Hierro en el sector central del Sistema Ibérico". En J. Arenas Esteban y M.V. Palacios Tamayo (coords.): El origen del mundo celtibérico. Junta de Comunidades de Castilla-La Mancha. Guadalajara: 191-211.

Armada, X.L.; Rafel, N. y Montero, I. 2008: “Contactos precoloniales, actividad metalúrgica y biografías de objetos de bronce en la Península Ibérica". En S. Celestino, N. Rafel y X.L. Armada (eds): Contacto cultural entre el Mediterráneo y el Atlántico (siglos XII-VIII ane). La precolonización a debate. Escuela Española de Historia y Arqueología en Roma, CSIC. Serie Arqueológica 11. Madrid: 465-508.

Arruda, A.M. 2008: "Estranhos numa terra (quase) estranha: os contactos pré-coloniais no sul do territorio actualmente portugués". En S. Celestino, N. Rafel, y L. Armada (eds.): Contacto cultural entre el Mediterráneo y el Atlántico (siglos XII-VIII ane). La precolonización a debate. Escuela Española de Historia y Arqueología en Roma, CSIC. Serie Arqueológica 11. Madrid: 355-370.

Barril, M.; Delibes de Castro, G. y Ruiz Zapatero, G. 1982: "Moldes de fundición del Bronce Final procedentes de El Regal de Pídola (Huesca)". Trabajos de Prehistoria 39: 369-383.

Benítez de Lugo, L.; Esteban Borrajo, G. y Hevia Gómez, P. 2004: Protohistoria y antigüedad en la provincia de Ciudad Real (800 a.C.-500 d.C.). C \& G, Puertollano.
Bernardini, P. 2008: "Dinamiche della Precolonizzazione in Sardegna". En S. Celestino, N. Rafel, y L. Armada (eds.): Contacto cultural entre el Mediterráneo y el Atlántico (siglos XII-VIII ane). La precolonización a debate. Escuela Española de Historia y Arqueología en Roma, CSIC. Serie Arqueológica 11. Madrid: 161-181.

Blasco, M. ${ }^{\mathrm{a} C}$. 1987: "Un ejemplar de fíbula de codo ad occhio en el valle del Manzanares". Boletín de la Asociación española de Amigos de la Arqueología 23: 18-28.

Blasco, M. ${ }^{\mathrm{a} C}$. 2007: "El tránsito del Bronce Final al Hierro Antiguo en la cuenca baja del Manzanares". Zona Arqueológica. Estudios sobre la Edad del Hierro en la Carpetania 10 (1): 64-87.

Blasco, M. ${ }^{a} C$.; Calle, J.R. y Sánchez-Capilla, M. ${ }^{\mathrm{a}}$ L. 1991: "Yacimiento del Bronce Final y de época romana en Perales del Río (Getafe, Madrid)". Arqueología, Paleontología y Etnografía 1: 37-148.

Brandherm, D. 2007: Las espadas del Bronce Final en la Península Ibérica y Baleares. Prähistorische Bronzefunde Abt. IV. Band 16. Franz Steiner Verlag. Stuttgart.

Cáceres, Y.E. 1997: “Cerámicas y tejidos: sobre el significado de la decoración geométrica del Bronce en la Península Ibérica". Complutum 8: 125-140.

Carrasco, J. y Pachón, J.A. 2006a: "Sobre la cronología de las fíbulas de codo tipo Huelva". Archivo de Prehistoria Levantina XXVI: 245-292.

Carrasco, J. y Pachón, J.A. 2006b: "La fíbula de codo tipo Huelva. Una aproximación a su tipología". Complutum 17: 103-119.

Celestino, S.; Rafel, N. y Armada, X.L. (eds.) 2008: Contacto Cultural entre el Mediterráneo y el Atlántico (siglos XII-VIII ane). La precolonización a debate. Escuela Española de Historia y Arqueología en Roma, CSIC. Serie Arqueológica 11. Madrid.

Ciudad Serrano, A. y Serrano Ciudad, J. 1986 "Poblamiento y culturas en la Prehistoria". En La Historia de la Provincia de Ciudad Real. Diputación Ciudad Real. Ciudad Real: 7-31.

Coffyn, A. 1985: Le Bronze Final Atlantique dans la Péninsule Ibérique. Diffusion de Boccard. París.

Delibes de Castro, G. 1978: "Una inhumación triple de la facies Cogotas I en San Román de Hornija (Valladolid)". Trabajos de Prehistoria 35: 225-250.

Delibes de Castro, G.; Fernández Manzano, J. y Herrán, J.I. 1994: "El depósito del Bronce Final de Pico Cuerno, Sotoscueva (Burgos): sobre la cronología y distribución de las hachas planas con anillas de la Submeseta Norte". Boletín de la Institución Fernán González 209: 239-277.

Delibes de Castro, G.; Fernández Manzano, J. y Herrán, J.I. 2007: "Los bronces de Valdevimbre y la metalurgia de Cogotas I". En J. Celis, G. Delibes, J. Fernández y L. Grau (eds.): El hallazgo leonés de 
Valdevimbre y los depósitos del Bronce Final Atlántico en la Península Ibérica. Estudios y Catálogos, 17. Museo de León, León: 106-131.

Delibes de Castro, G.; Fernández Manzano, J.; Fontaneda, E. y Rovira Llorens, S. 1999: Metalurgia de la Edad del Bronce en el piedemonte meridional de la Cordillera Cantábrica. La Colección Fontaneda. Arqueología en Castilla y León 3. Junta de Castilla y León. Zamora.

Delibes de Castro, G.; Romero Carnicero, F.; Sanz Martínez, C.; Escudero Navarro, Z. y San Miguel Mate, L.C. 1995: "Panorama de la Edad del Hierro en el Duero Medio". En G. Delibes de Castro, F. Romero y A. Morales (eds.): Arqueología y medio ambiente. El primer milenio A.C. en el Duero Medio. Junta de Castilla y León. Valladolid: 49-146.

Díaz-Andreu, M. 1988: "El análisis discriminante en la clasificación tipológica: aplicación a las hachas de talón de la Península Ibérica". Boletín del Seminario de Estudios de Arte y Arqueología LIV: 25-64.

Fernández Manzano, J. 1986: Bronce Final en la Meseta Norte Española: el utillaje metálico. Junta de Castilla y León. Almazán.

Fernández Rodríguez, M. y Rodríguez de la Esperanza, M.'J. 2002: "Los depósitos de armas en el Bronce Final: Un nuevo hallazgo en Puertollano (Ciudad Real)". Trabajos de Prehistoria 59 (2): 113-133.

Figueiredo, E.; Ávila de Melo, A. y Araújo, M.F. 2007: "Artefactos metálicos do Castro de Pragança: um estudo preliminar de algumas ligas de cobre por Espectrometría de Fluorescência de Raios X". O Arqueólogo Portugués Serie IV, 25: 195-215.

Gallart i Fernández, J. 1991: El dipòsit de bronzes de Llavorsí: Pallars Sobirà. Excavacions arqueologiques a Catalunya 10, Direcció General del Patrimoni Cultural. Servei d'Arqueologia. Barcelona.

Gil-Mascarell, M. y Peña, J. L. 1989: "La fíbula ad occhio del yacimiento de la Mola d'Agres". Saguntum 22: 125-146.

González Prats, A. 2002: La necrópolis de cremación de Les Moreres. (Crevillente, Alicante, España) (s. $I X$-VII $A C$ ). Universidad de Alicante. Alicante.

Hardaker, R. 1976: "Las hachas de cubo en la Península Ibérica". Cuadernos de Prehistoria y Arqueología Castellonense 3: 151-171.

Harrison, R.J. y Craddock, P.T. 1981: “A study of Bronze Age Metalwork from the Iberian Peninsula in the British Museum". Ampurias 43: 113-179.

Herrán, J.I. 2008: Arqueometalurgia de la Edad del Bronce en Castilla y León. Studia Archaeologica 95. Universidad de Valladolid. Valladolid.

Jockenhövel, A. 1982: “Zu den ältesten Tüllenhämmern aus Bronze”. Germania 60: 459-467.
Lopes, C. y Vilaça, R. 1998: "Peça do Bronze Final proveniente do 'Pé do Castelo' (Trindade, Beja)". Arquivo de Beja [Serie III] 7-8: 63-84.

Lorrio, A. 2008: Qurénima. El Bronce Final del Sureste de la Península Ibérica. Bibliotheca Archaeologica Hispana 27, Real Academia de la Historia. Madrid.

Lo Schiavo, F. 1985: Il ripostiglio del Nuraghe Flumenelongu (Alghero-Sassari). Considerazioni preliminari sul comercio maritimo nel Mediterraneo occidentale in età protostorica. Soprintendenza alle antichità per le provincie di Sassari e Nuoro. Quaderni II. Sassari.

Lo Schiavo, F. 1991: "La Sardaigne et ses relations avec le Bronze Final Atlantique". En C. Chevillot, y A. Coffyn, (eds.): L'Âge du Bronze Atlantique. Actes du I colloque du Parc Archéologique de Beynac. Publications de la Association de Musées Sardalais. Beynac-et-Cazenac: 213-226.

Lucas, R.; Gutiérrez, C.; Blasco, M. ${ }^{\mathrm{a} C}$. y Rovira, S. 2005-2006: "El depósito de Miedes y otros materiales metálicos (Bronce Final/Hierro I) procedentes de la provincia de Guadalajara". Boletín de la Asociación Española de Amigos de la Arqueología 44: 129-160.

Martí, F. 1969-1970: "Las hachas de Bronce en Cataluña”. Ampurias 31-32: 103-131.

Mederos, A. 2008: "Las espadas de tipo Huelva y los inicios de la presencia fenicia en Occidente durante el Bronce Final IIC-IIIA 1150-950 AC'. Cuadernos de Prehistoria y Arqueología de la Universidad Autónoma de Madrid 34: 41-75.

Misiego, J.C.; Villanueva, L.A.; Marcos, G.J.; Martín; M.A. y Sanz, F. J. 2005: "Guaya (Berrocalejo de Aragona, Ávila): Reconstrucción de la vida y economía de un poblado de los albores de la Edad del Hierro". En C. Cancelo, A. Esparza y A. Blanco (coords.): Encuentro de Jóvenes investigadores sobre el Bronce Final y Hierro en la Península Ibérica (Salamanca 2003): 197-218. Salamanca.

Monteagudo, L. 1977: Die Beile auf der Iberischen Halbinsel. Prähistorische Bronzefunde, Abt. IX, band 6. C.H. Beck'sche Verlagsbuchhandlung. Munchen.

Montero, I.; Fernández, M.; Gómez, B. y Ontalba, M.A. 2002: "Espadas y puñales del Bronce Final: el depósito de armas de Puertollano (Ciudad Real)". Gladius XXII: 5-28.

Monteverde, J.L. 1969: "La colección Monteverde de Burgos (I)". Noticiario Arqueológico Hispánico X-XII (1966-1968): 225-234.

Penedo, E.; Sánchez, M.; Martín, D. y Gómez, E. 2001: "La necrópolis de incineración de la Primera Edad del Hierro en Arroyo Culebro (Leganés)". En E. Penedo (comp.): Vida y muerte en Arroyo Culebro (Leganés). Museo Arqueológico Regional. Madrid: $45-70$. 
Pereira, J. 2007: "El Bronce Final y los inicios de la Edad del Hierro". En J. Pereira (coord.): Prehistoria y Protohistoria de la Meseta Sur (Castilla-La Mancha). Almud, ediciones de Castilla-La Mancha. Ciudad Real: 127-158.

Pérez, R.; Vizcaíno, D.; Barrachina, A.; Viciach, A.; Sanchís, A.; Tormo, C. y Haro, S. 2007: "Sant Joaquim. Evidencias de un hábitat del Bronce Final". En D. Vizcaíno y R. González (eds.): Paisaje y arqueología en la Sierra de la Menarella. Estudios previos del Plan Eólico Valenciano. Zona II: Refoies y Todolella. Renomar S.A. y EIN Mediterráneo SD.L. Valencia: 167-184.

Pons, E. 1979-1980: 'El dipòsit d'objectes de 1'Edat del Bronze, de Ripoll". Annals de l'institut d'Estudis Gironins XXXV-XXXVI: 59-78.

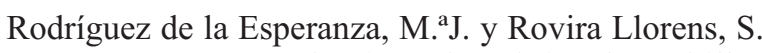
2005-2007: "Metalurgia en la Fábrica de Ladrillos de Preresa (Getafe, Madrid)". Estudios de Prehistoria y Arqueología Madrileñas 14-15: 167-170.

Rovira Llorens, S. 1995: "Estudio arqueometalúrgico del depósito de la Ría de Huelva". En M. ${ }^{a} L$. Ruiz-Gálvez (ed.): Ritos de Paso y Puntos de Paso. La Ría de Huelva en el Mundo del Bronce Final Europeo. Complutum Extra 5. Madrid: 33-57.

Rovira Llorens, S. 2004: “Tecnología metalúrgica y cambio cultural en la Prehistoria de la Península Ibérica". Norba 17: 9-40.

Rovira Llorens, S. y Gómez Ramos, P. 1994: "Punzones y varillas metálicas en la Prehistoria Reciente española: un estudio tecnológico". Espacio, Tiempo y Forma, Serie I, 7: 371-402.

Rovira i Port, J. y Casanovas i Romeu, A. 1993: “Los brazaletes de Sant Aleix (Lleida) y los depósitos de objetos metálicos del Bronce Final en Cataluña”. Complutum 4: 69-80.

Ruiz-Gálvez, M. ${ }^{a}$ L. 1993: “El Occidente de la Península Ibérica, punto de encuentro entre el Mediterráneo y el Atlántico a fines de la Edad del Bronce". Complutum 4: 41-68.

Ruiz-Gálvez, M. ${ }^{a} L$. 1995: “Cronología de la Ría de Huelva en el marco del Bronce Final de Europa

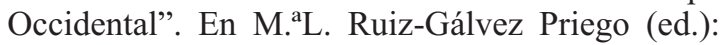
Ritos de Paso y Puntos de Paso. La Ría de Huelva en el mundo del Bronce Final Europeo. Complutum, Extra 5: 79-83.
Ruiz-Gálvez, M.'L. 1998: La Europa atlántica en la Edad del Bronce. Un viaje a las raíces de la Europa occidental. Editorial Crítica. Barcelona.

Ruiz-Gálvez, M. ${ }^{a}$ L. 2005: "Der Fliegende Mittlemeermann. Piratas y héroes en los albores de la Edad del Hierro". En S. Celestino y J. Jiménez (eds.): El Período Orientalizante. Actas del III Simposio Internacional de Arqueología de Mérida: Protohistoria del Mediterráneo Occidental. Anejos de Archivo Español de Arqueología XXXV, I: 251-275.

Sierra Rodríguez, J.C.; Vázquez, A.; Luis, L de. y Ferreira, S. 1984: El depósito del Bronce Final de Samieira. Boletín Auriense. Anexo 2. Orense.

Soriano Sánchez, R. 1991: Catálogo de fondos prehistóricos municipales. Ajuntament de València. Serie Arqueológica 7. Valencia.

Talma, A.S., y Vogel, J.C. 1993: “A Simplified Approach to Calibrating C14 Dates". Radiocarbon, 35 (2): 317-322.

Taramelli, A. 1921: "Il Ripostiglio dei bronzi nuraghici di Monte Sa Idda, di Decimoputzu (Cagliari)". Monumenti Antichi XXVII: 5-108.

Torres, M. 1999: Sociedad y mundo funerario en Tartessos. Real Academia de la Historia. Madrid.

Turco, M. ${ }^{\mathrm{a} G}$. 2000: La necrópolis di Cassibile. Cahiers du Centre Bérard XXI. Nápoles.

Urbina, D.; Morín, J.; Ruiz, L.A.; Agustí, E. y Montero, I. 2007: "El yacimiento de Las Camas, Villaverde, Madrid. Longhouses y elementos orientalizantes al inicio de la Edad del Hierro, en el valle medio del Tajo". Gerión 25 (1): 45-82.

Vilaça, R. 2004: "Ecos do mediterrâneo no Monte de São Martinho (Castelo Branco): a propósito de um artefacto do Bronze Final". Estudos Castelo Branco, Nova Serie 3: 5-18.

Vilaça, R. 2008: "Reflexões em torno da "presença mediterrânea" no centro do territorio portugués, na charneira do Bronze para o Ferro". En S. Celestino, N. Rafel, y L. Armada (eds.): Contacto cultural entre el mediterráneo y el atlántico (siglos XII-VIII ane). La precolonización a debate. Escuela Española de Historia y Arqueología en Roma, CSIC. Serie Arqueológica 11. Madrid: 371-400.

Vives-Ferrándiz Sánchez, J. 2005: Negociando encuentros: situaciones coloniales e intercambios en la costa oriental de la Península Ibérica (S. VIII-VI a.C.). Cuadernos de Arqueología Mediterránea 12. Barcelona. 